\title{
FIRST YEAR MATHEMATICS COURSES
}

"A critical study of the purpose, farm, content and organization of first year mathematics work at

the University of Missouri and elsewhere, with a view to finding the courses in mathematics best suited for use in

first year college and university wcrk in general".

\author{
By \\ Albert Heinz \\ A.B., B.S.
}

1910

\section{Submitted in partial fulfilment of the requirements for the degree of MASTER of ARTS} 1916.

In the GRADUATE SCHOOL University of Missouri Columbia Mo. 
$378.7 M 71$

XH365

$142565^{59}$ 


\section{FIRST YEAR MATHENATICS COURSES.}

\section{OUTLINE}

FOREWORD.

1. Orientation of the purpose and field of this study. p.i.

2. Description of Tsing Hua College, Peking China. p.2PURPOSES.

p. 5 .

1. To study the status of first year mathematics courses

at the University of Missouri, in their relation to secondary school mathematics, in their relation to further university work, and in relation to the extent to which the present organization of courses fulfils the purposes of those courses.

2. To suggest ways and means of making first year university mathematics courses in general best serve their largest purposes and possibilities.

3. To further prepare the writer to best serve his opportunity and responsibility in the peking school.

\section{BODY OF THESIS.}

1. Chapter 1 .

a. Intrcaction, showing purpose of studying the status of secondary school mathematics in Missouri and in the Peking school. p. 6 .

b. Description of mathematics courses in the Pekina school.

c. Mathematics in the secondary schcols of Missouri, with some general observations on the secondary schools in general. 
2. Chapter 11 .

a. Intrcaction, dircting attention Table No. 111 , which shows the amounts of mathematics offered for entrance credit by students entering the University of Missouri at different periods of time, these students being considered in various groupings. p.i5.

b. Expla nation of the mechanism of Table No. 111 . p.15:-

c. Statement of the fundamental purpose of the table mentioned above, i.e. Table No. III. D. 16.

d. Some general observations drawn from part of the data of Table No. I11. p.16--

3. Chapter 111 .

a. Introduction, describing roughly the three types of students served by first year mathematics courses at the University of Missouri, and describing briefly the three different mathematics courses open to these students. p. 19 .

b. Description and discussion of the General Mathematics course, Course 8 0.20--

c. Description and discussion of the Elementary Analysis course, Course 1.

d. Description and discussion of the Trigonometry and Algebra courses, Course 3 (Norm) and Course 3(slow) D. 26-t)

$\theta$. Distribution of Arts and Engineering students in the first and second semester first your courses. p.27xf. Distribution of grades between Arts and Engineering students, and among the different first year courses:- 
4. Chapter IV.

a. Introduction, announcing purpose of the chapter as being that of suggesting some ways and means of making first year mathematics courses serve their purposes.p. 31.

b. General Mathematics, Course 8, discussed, and a new course proposed.

$0.31--$

c. Discussion of selection of students for course 1 , and discussion of texts for course 1. 0.33--

d. Mathematics courses for students taking but one semester of first year mathematics. $\quad 0.35 \div-$

e. Criticism of present plan of segregating first year mathematics students acc.ording to ability. 0.37--

f. The need of a Freparation course in mathematics pointed out, and definite suggestions offered. p.39--

g. The selaration of Arts and Engineering students in first year mathematics courses proposed.

h. The question, Have the first year mathematics courses been changed in content and intensity within the past few years, and why," proposed for further study. 0..46.

i. Discussion of the problem reader system. p.47.

j. A summary of the present orqanization and of the writer's proposed organization of first year mathematics courses. p. 48.

5. Chapter V.

a. Introduction, summarizing the objects of the preceding chapters, and orientating the discussions cfound in Chapter V. p. 50 . 
b. Survey of the field of first year mathematics, and an outline of the courses needed in this field. p.50-c. Discussion of text books and the ideas they embody. p.55--

d. Summary of previous discussion regarding separation of students into different types of first year courses. $0.57--$

e. Resume of the orientation of this study and of further studies contemplated by the writer.

p. $59--$ BIBLIOGRAPHY. p. $61--$ 


\section{FIRST YEAR NATHEMATICS COURSES.}

\section{LIST OF TABLES.}

1. Table No. 1. Percentages of the total number of students in accredited high schools of Missouri studying different groups of subjects at different times. (From the Missouri school Report for $19 i 4$ and for igi5.) p.12.

2. Table No. 11. Entrance units per student offered by students entering the University of Missouri at different times. (From entrance cards in Registrar's office).

3. Table No. III. Amounts of mathematics offered for entrance credit by various groups of students entering the University of Missouri at various periods of time. This is a condensed table which is broken up into parts, amplified, and used, in later discussions. (From Registrar's records). f.p.l5.

4. Table No. IV. Part C of Table No. III. Comparing percentage of students entering the University in Fall of 1915 having previously studied Triqonometry, with rercentage of situdents $(1902-14)$ entering the University prior to is $14^{1}$ having previously studied Trigonometry.

5. Table No. V. From various parts of Table No. III. Comparing amounts of mathematics offered for entrance to the University by Engineering Students, by male Arts students, and by female studemts, in corresponding groups and at copresponding times.

6. Table No. VI. From Table No. IIl, Part A, row I. Showing amounts of mathematics offered for entrsnce by men and by 
women students in General Mathematics, Course $8 . \quad$ p. $2 i$.

7. Table No. VII. Number and percentage of Arts and of Engineering students in each of the 5-hour first year p. 27. courses, Fall 1915. (From records in Mathematics office)

8. Table No. VIIl. Showing the number of Arts and of Engineering students in each of the 5-hour courses in the first semester of 1915-16, and the number and percentage who take the following second semester courses. (From records in the Mathematics office) p.28.

9. Table No. IX. Showing the number of Eas, M, I, F, I \&.F, grades qiven to Arts and to Engineering students in each of the three 5-hour first semester first year mathematics courses. (From records in the Mathematics office). 0.29.

10. Table No. X. Comparing the number and percentage of total number of $E \& S, M, I, F, I \& F$, grades given to all first year 5-hour course students, these grades being distributed according to the three courses. (From Table $N c^{\prime},|X|$. p. 30 .

A. Table No. A. Showing grades made in Calculus classes during past ten years by Education students and by Engineering students, in b.cth cases only those students who have graduated or who are still in school being considered. (From records in Mathematics office and the student directory and alumni directory.. $\quad 0.30$.

B. Table No. B. Schedule for all first year mathematics courses proposed by the writer.. 
FIRST YEAR MATHEMATICS COURSES.

"A critical study of the purpose, form, content and organization of first year mathematics courses at the University of Missouri and elsewhere, with a view

to finding the courses best suited for use in first year collegiate and higher mathematics work".

FOREWORD:

The writer of this paper is at present connected with a Chinese Government schcol in Peking China, t is his privelege to determine, to a great extent, the form and conelementary tent of the mathematics courses from fourth grade, school to sophomore university grade of work. The problem immediately to hand in the Peking school is the more complete organization and motivation of that mathematics material usually found in first year university and college mathematics courses. These first year courses, it seems, form the key to the whole mathematics situation, in that they reflect back onto and essentially depend upon the secondary school mathematics and also distinctly prevare for and color further university work in mathematics and in other subjects as well. Hence the selection of this subject of study: Mathematics courses, because Mathematics is the writer's special department in the whole field of Education; and First Year courses, because they control, in a way, the whole mathematics situation. 
A brief description of the purposes and working of the Peking school will serve to better show the relation of the writer's work in that school to this study, and will also serve as a description of a unique unit in the field of Education at large.

In 1908 the United States Congress voted to return to China a portion of the 1900 Boxer Indemnity, each year, just as the money was paid in to the United States by China. About eleven million dollars of the assessed twenty four million was to be returned, the period of this Boxer Indemnity extending over about forty years. China ap preciated this act of national good-will, and for the purpose of furthering friendly relations between the two countries, decided to use this returned money in educating Chinese young men (and women) in the universities and technical schools of America. Accordingly, a Board of Educational Mission to America was established, according to the directions drawn up by H.E.Yuan Shih-k'ai, in Peking, for the ourpose of selecting and sending out the students on this fund. It was planned to send an average of about fifty students each year, these students to remain in the United States for five years of study. In carrying out this scheme it was found necessary to establish in. Peking a special school for preparing these students to get most out of their allotted time in America. Hence the establishment of TSING HUA COLLEGE, to which school the writer returns after this (1915-16)year's leave of absence. 
This fund mentioned above supports the school at Peking very generously and provides liberally for the fifty students sent to America each year during their five years' study in the best American colleges and universities. At present the students sent out enter easily into second year university work. Upon returning to China they are put into government and civil positions, the opportunities and responsibilities of which far exceed those of the positions into which American young men of corresponding school training are able to place themselves.

Fifty students only of the one hundred sixty who enter the school at Peking are allowed to go on to the completion of the course and consequent study in America. The average Chinese students compare favorably with American students, and these specially selected students in the feking school, with a considerable material incentive, form an exceedingly teachable group of students.

The purpose of the school, as indicated, is to prepare who are

these students to be sent to America to aet most out of their five years' study, and to inspire them to find and to bring back to China that which shall be of most lasting value to the people of China. This preparation means more than the mere teaching of subjects pre-requisite to second year university work. It means a motivation of study in the largest sense, a developing and directing of ideals and ambitions, and the inspiring of the students to seek out that in America which they can carry back and USE in their own land. 
The curriculum and general teaching plans follow roughly those of the American public school system from about fourth elementary grade a school to second year university grade of work, the students entering at about twelve or fourteen years of age and completing the course in eight years. In these eight years they master the English language to a high degree of efficiency, acquire a fairly liberal Chinese education, build up a strong, healthy physique from the proverbial Chinese scholar's frailty, and also cover all the subjects pre-requisite to second year university work in America.

We have, in the Peking school, a field very much freed from 'traditional' bounds, and as such it can contribute, and is contributing, some things of value to the whole field of education in China. Thus we see the scope of the field of the Peking school is as wide as the scope of education itself. But to pick from this whole field of educational problems one within the limits of this study, the writer has settled on that of the First year Mathematics courses for Colleges and Universities, since this field of investigation will not only be of value to the writer in his work in the Peking school, but it is a field well worthy of investigation within the University of Missouri itself and throughout the whole field of collegiate mathematics.

The re-organization of the "American Mathematical Monthly", and the recently organized "Mathematical Association of America" point out the recognized need of investigation and study in the field of collegiate mathematics. Hence this study is made. 
PURPOSES OF THIS STUDY:

To summarize and state definitely the general purposes of this study, we find them to be these:

1. To find out and to record the actual purposes, form, content and organization of first year mathematics courses at the University of Missouri and elsewhere, this study necessarily leading back into a survey of the secondary school mathematics situation and anticipating certainly the students' further university work.

2. To discover to what extent the courses as now organized fulfil their purposes.

3. To suggest, where possible, some constructive methods for making first year mathematics courses more fully realize their purposes, and to carefully formulate what these purposes are and suggest wherein they might be modified or enlarged.

4. To contribute to the University of Missouri and to the field of mathematics and education at large, any positive results of interest in the field of collegiate mathematics. 5. To further prepare the writer to more fully and efficiently serve his oppertunity and responsibility in that phase of educational work which demands a professional knowledge of the subject, the field of work lying in the conduct of the Department of Mathematics in the school at Pekina; Tsing Hua College. 


\section{CHAPTER 1.}

A survey of the status of mathematics in the Peking school and in the high schools of Missouri.

Introduction:

Any study of the first year university mathematics courses demands, it seems, some knowledge of the secondary school mathematics courses preparatory to the university courses. In this survey of the status of mathematics in the secondary schools we cannot avoid meeting up with the general problem of secondary school courses in general. Here we cannot hope to do more than point out some general tendencies in secondary school instruction and point out some lines of work in this important field.

1. Mathematics in the Pekina school:

One purpose of this study being that of preparing the writer to more efficiently organize the first year university grade of mathematics work in the Peking school, it will be highly desirable at this point to give a rather careful review of the mathematics work now being done in that school. The mathematics work in each of the eight grades will be described, this work beginning with about fourth grade elementary school Arithmetic and finishing with Analytic Geometry. So far as mathematics is concerned, the students completing these courses are fully ready for the Calculus.

1. First year 'Middle School'. Here is given a 3-hour course in Elementary Arithmetic in Chinese by an English-speaking Chinese teacher. The learning of Arithmetic and the learning 
of English thereby occupy about equal portions of the student's energies. The subject matter of this year's work is similar to that found in the Stone-Hillis Intermediate Arithmetic.

2. Second year 'Middle School': In this year the 3-hour Arithmetic course is given in English by an English-speaking Chinese teacher. The Stone-Hillis Intermediate Arithmetic is used as a text along with application prablems from chinese every-day I ife.

3. Third year 'Middle School': The work in this year is in process of organization. It purposes to complete the subject of Elementary Arithmetic as usually understood, to include some commercial and business phases of Arithmetic, to introduce manual training by way of lighter manual arts work and to make excursions into the activities in and outside the school.

4. Fourth year 'Middle School': This grade corresponds roughly to first year American high school. The formal study of Algebra is here taken up, the arithmetic phase being most fully emphasized. The Hawkes-Luby-Touton First course in Algebra is used as a text, and American teachers entirely conduct the class work. entirely in English.

5.. First year 'High School': Algetra is continued in this year, the class completing in a 2-or 3-hour course the second Course in algebra of the above authors. The students seem to be more mature and more capable of appreciating this grade of work than are American students of corresponding school age.. 6. Second year 'High School': Here is given a 4-hour standard 
course in Plane Geometry, correlating with advanced manual training work and elementary mechanical drawing work. The Stone-Millis Plane Geometry is used as a text. The exercises and outside problems are worked out carefully and neatly,unruled loose-leaf note book paper being used.

7. Third year'High School': The writer has given special attention to the work of this year, the other courses more nearly following the traditional lines. But in Solid Geometry and Trigonometry there seemed to be found the most fruitful and most imperative field for careful analysis and organization of purpose and form of the course. A full semester of 4 hours a week is all cwed for each of these courses. The students, moreover, have ample maturity and capacity for developing very liberal courses.

The Solid Geometry course includes not only all the usual facts of this subject, but it also includes a wider range of topics, such as those primarily connected with the conception and measurement and representation of space objects. The logical training aspect of geometry is made less the feature of the course than is the development of the powers of sace rerception, and the study of mathematical processes and facts worth while in themselves. The Stone-Millis Solid Geometry is used as a text for reference mainly. Many of the topics of the text are widened and generalized and carried over into other fields. The method of presenting the THEOREXS often differs widely from that of the text. Instead of stating all the facts of a theorem and then asking the student to 'orove' 
that which has just been stated as a fact, the proposition is put tc him in this way, taking a special case to illustrate: "Consider the line running from the vertex of a pyramid to the middle point of its (triangular, parallelogram, rectangle, polygon) base. Is there any relation between the length of this line and the lengths of the lateral edges and the edges of the base". The study of this proposition will lead the student to actually discover the fact for himself that the length of this line can be found in terms of the edges when the base is of a certain shape. A proposition of this kind arouses within the student a thirst for individual discovery, the development and organization of which is of far greater value to the student than is his mere possession of the facts of the theorem or his ability to go through an apparently futile proof.

The Trigonometry course follows a standard text, Rothrock's plane and Spherical Trigonometry, covering not only the solution of triangles, but including as the fundamental basis of the course that phase of mathematics which has to do with problems of ROTATION and consequent ANGLE FORMATION. The course is quite complete and thorough, since the students cone into the course with more liberal and more uniform preparation than is the case in first year university Trigonometry courses.

8. Fourth year 'High School': Only the scientific course students take mathematics in this year. In the first semester is given a 5-hour course in Advanced Algebra, using Fite's college Algebra as a text with Fine's College Algebra for 
supplementary work. More topics are covered and in a more rigorous and complete manner than are covered in the Algebra part of the first year mathematics course at the University of Missouri. A full semester is allowed for the Algebra alone. The students have uniform preparation in preceding subjects.

The second semester is given to Analytic Geometry. A standard course is at present qiven. From this course the students enter into the Calculus in American universities, their equipment being uniform, complete and liberal.

The more complete organization and motivation of these fourth year 'High School' courses is the writer's immediate problem in the Peking school. Moreover, higher courses are to follow these in succeeding years as the school expands, year at a time, into a full-course university. Hence, partly, this particular study at a representative American university is made. 11. Mathematics in the American secondary schools:

The status of mathematics in the secondary schools cannot be discussed as a topic independent and complete in itself. Mathematics work must be considered as a part of the whole scheme of the secondary schools. This would lead us into a study of the whole field of secondary school education, which field, isteresting and fruitful as it is, we cannot here enter. We can, however, well afford to observe some of the general tendencies, these quiding the study of any particular subject. What follows here should be taken to indicate lines of study rather than the results of any complete study. 
A significant change is taking place in the very purpose and form of the public secondary schools. There is a change from the conception and organization of the high school as a 'college preparation' or a 'cultural and intellectual development' type of school, to the conception and organization of the high school as the "boys' and girls' university" type of school, using the word University in the sense in which it identifies State universities of America. Both the State Universities and the public high schools are supported by the people of the State, for the needed training of the young people of the State, all for the ultimate service of the reople of the state as well as for the service of the individuals themselves. Just as the State universities, with their definite and imperative purposes have grown up cut of the more purely 'cultural' and 'intellectual development' colleges of the past and of to-day, so also is the new high school growing up out of the 'preparation for college' and more purely mental discipline' and 'intellectual development' high schools of the past and of the present. Certainly intellectual development and preparation for college are not to be lost sight of; we only insist that this new form and purpose of the public high schools be not too reluctantly given its place in the free and impartial public educational system of the state.

This new spirit in the high schools----with its resultant change in curriculum of the high schools---- might easily be mistaken for all sorts of deteriorations by various persons viewing the situation from the standpoint of one par- 
ticular subject. For instance, the mathematics man might be alarmed upon learning that the percentage of pupils in the high schools studying mathematics is, in the last three years, four percent less than it was in the 07-c8-09 three year period. And if the mathematics man be alarmed because of this dropping off in mathematics, more so the science (older sciences) and Latin people upon learning that there has been a nine rercent and a fifteen percent, respectively, dropping off of pupils in the high schools studying these subjects. The table below shows the percentage of all pupils in the high schools of Missouri studying the different groups of subjects listed, at three different periods of time, viz. 07-08-09, 10-11-12 and 13-14-15. The group of subjects headed science includes all sciences EXCEPT Agriculture and Domestic Science. The group of subjects headed Vocational includes such subjects as Drawing, Book-keeping and Type-writing, Manual Training, Teacher Training and Pedagogy, etc. (Compiled from Missouri Report of Public schools, igi5, page 341 ).

$$
\text { TABLE NO. } 1 .
$$

Percentages of pupils studying different subjects in the 3-year periods 07-08-09, 10-11-12, 13-14-15.

$\begin{array}{lcccc}\text { Percent Studying: } & 07-08-09 & 10-11-12 & 13-14-15 & \text { Ratio 1 } \\ \text { Mathematics } & 95 \% & 93 \% & 91 \% & .96 \\ \text { Sciences (older) } & 41 \% & 37 \% & 32 \% & .78 \\ \text { Latin } & 54 \% & 47 \% & 39 \% & .72 \\ \text { English } & 95 \% & 95 \% & 95 \% & 1.00 \\ \text { History \& Economics } & 69 \% & 69 \% & 71 \% & 1.03 \\ \text { Modern Languages } & 17 \% & 19 \% & 19 \% & 1.12 \\ \text { Vocational } & 30 \% & 32 \% & 45 \% & 1.50 \\ \text { Agr. \& Dom. Science } & 12 \% & 18 \% & 35 \% & 2.92\end{array}$


The table on the preceding page explains itself. As has been pointed out, the high school is changing from the more purely college preparation type to the more nearly life preparation type. The table fully bears out this observation. Mathematics and Latin and the older sciences are losing oupils to the newer subjects---if in consequence of the poor teaching of these subjects, then there is cause for warry. But there should be no wild attempt made to turn mathematics courses into carpentry, or Latin into a study of Roman hair-dressing or a subject like Chemistry into a course in candy-making. Let these subjects in themselves be improved and made of most consequence, by the proper teaching of the subjects; $\ldots$ not force them into fields already adequately taken care of by the proper courses. This again is for the student of the pedagogy of each individual subject, working in sympathetic and understanding connection with the student of the purpose and form of the high school organization in general.

One more paragraph regarding secondary schools in general: This study is concerned particularily with the students who enter the Aniversity, hence we shall here note the preparation in various subjocts with which students come into the university. The table on the following page shows the number of units (and percentage of whole) in the various subjects, offert od at various times, for entrance to the University of Missouri. These figures are calculated from the entrance in the Registrar's whose names bogin with $M$, studentsichosen at random, for each period of time mentioned. (These recards cover the years to 1915 . More entrance units were offered in 1915 than prior to 1909. 
This total increase in number of units offered makes it necessary to compare the percentages for each subject, of the number of units offered. (Units per student listed below).

TABLE 11 .

Number and percentage of entrance untts in various subjects offered by students entering at three periods of time.

\begin{tabular}{lrrrr} 
Units offered: & Prior to. 1909 & In $11-12-13$ & In Fall 1915 \\
Mathematics & $3.0=21.6 \%$ & $3.0=19.4 \%$ & $3.0=18.0 \%$ \\
Sciences (older) & $1.6=11.9 \%$ & $1.8=11.5 \%$ & $1.8=10.7 \%$ \\
Latin & $2.4=17.8 \%$ & $2.2=14.6 \%$ & $2.4=14.5 \%$ \\
English & $3.4=24.6 \%$ & $3.8=24.9 \%$ & $3.9=23.5 \%$ \\
Hist \& Economics & $2.6=19.2 \%$ & $2.9=19.0 \%$ & $3.7=22.5 \%$ \\
Modern Languages & $.5=3.5 \%$ & $1.0=6.3 \%$ & $.8=4.7 \%$ \\
Vocational & $.2=1.5 \%$ & $.5=3.3 \%$ & $.6=3.6 \%$ \\
Agr.\& Dom.Sc. & $0.00=0.0 \%$ & $.2=1.2 \%$ & $.4=2.4 \%$ \\
Total per student $13.7=100 \%$ & $15.3=100 \%$ & $16.5=100 \%$ \\
\hline
\end{tabular}

From the above table we readily seo that the greatest docrease in percentage of all subjects offered for entrance in 1915 as compared with the years prior to $1909,{ }_{1}$ occurs in Nathematics and Latin. The percentages of History\& Economics, Vocational subjects, Science (all sciences), and Modern Langua\$es, have increased in corresponding xears. Thus students are now coming to the university with less of the former and more of the latter named subjects. So far as mathematics is concernod, the writer sees in this no serious cause for alarm. A student's maturity and diversity of training are bigger assots, It seoms, than the mere knoweledge of a little more of any one subject, as preparation for further work in that subject. Notice the magnitude of the percentages for different subjects. 
TABLE NO. H11. (numbers)

Divisions of students according to units in mathematics offered for entrance.

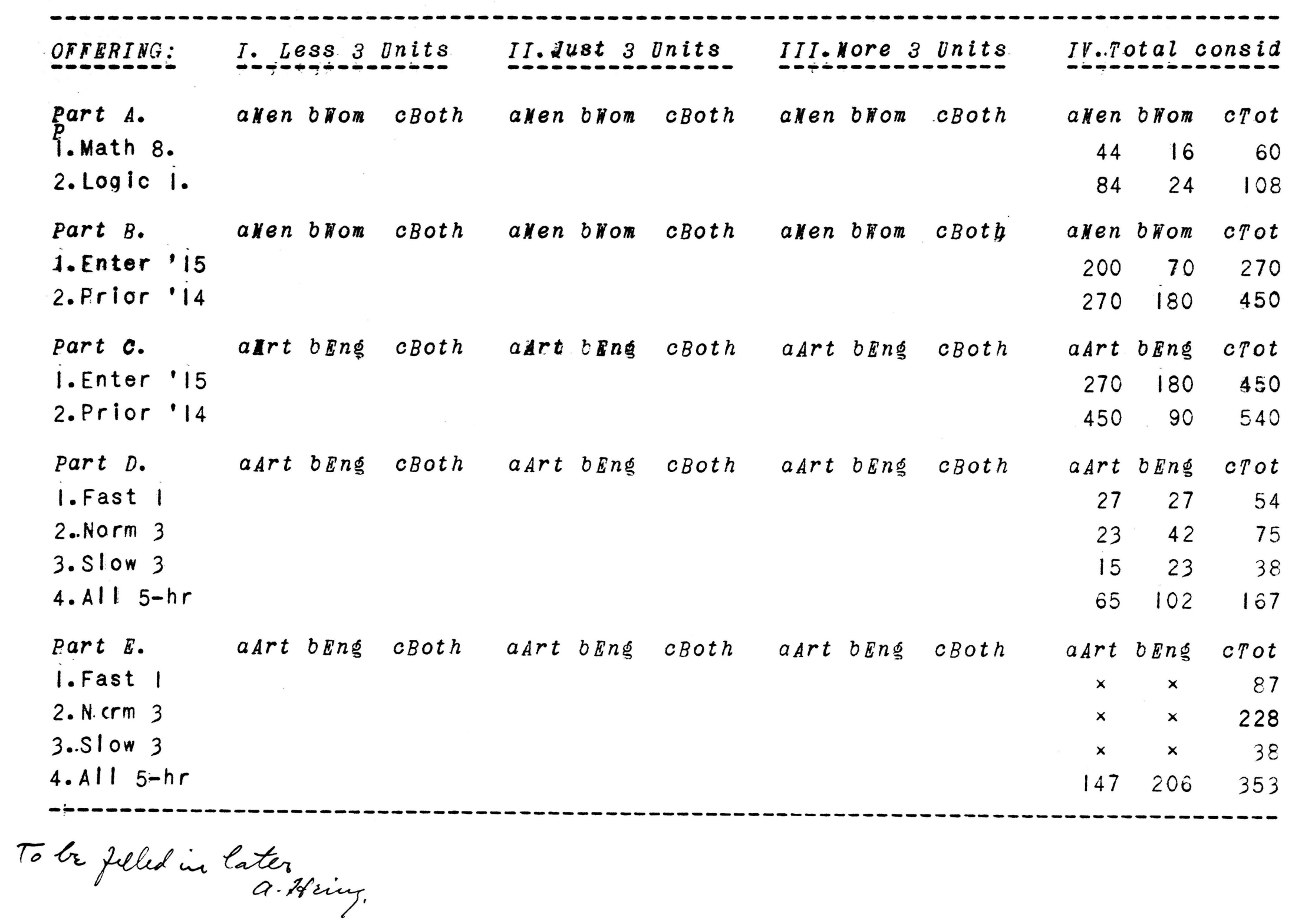


TABLE NO.111.

Division of students according to units offered in mathematics cor entrance..

\begin{tabular}{|c|c|c|c|c|c|c|c|c|c|c|c|}
\hline OFFERIHG: & $I . L E$ & ss 3 & Units & II.JU & $\operatorname{cst}$ & Units & $I I I$. & Yore & Onits & $I V . T C$ & a) \\
\hline art $A$. & aken & bitom & $c B \circ t h$ & allen & b Tom & $c B o t h$ & allen & b hom & cBoth & allen & bHom \\
\hline 1. Math 8 & $30 \%$ & $69 \%$ & $40 \%$ & $34 \%$ & $25 \%$ & $32 \%$ & $36 \%$ & $6 \%$ & $28 \%$ & $44=73 \%$ & $27 \% \quad 60=100 \%$ \\
\hline 2. Logic 1 & $36 \%$ & $75 \%$ & $45 \%$ & $39 \%$ & $12 \%$ & $33 \%$ & $25 \%$ & $13 \%$ & $22 \%$ & $84=78 \%$ & $22 \% 108=100 \%$ \\
\hline art $B$. & allen & bWom & cArts & aken & bHom & cArts & alyen & brom & cArts & allen & bNom \\
\hline 1. Enter 15 & $31 \%$ & $43 \%$ & $34 \%$ & $33 \%$ & $29 \%$ & $30 \%$ & $36 \%$ & $28 \%$ & $34 \%$ & $200=74 \%$ & $26 \% 270=100 \%$ \\
\hline 2. Prior '/4 & $30 \%$ & $42 \%$ & $35 \%$ & $46 \%$ & $43 \%$ & $44 \%$ & $24 \%$ & $15 \%$ & $21 \%$ & $270=60 \%$ & $40 \% 450=100 \%$ \\
\hline art $c$. & $\operatorname{aArt}$ & $b E n g$ & $c B o t h$ & $a A r t$ & $b E n \xi$ & $c B o t h$ & $a A r t$ & $b E n g$ & $c B o t h$ & $a A r t$ & $b E n g$ \\
\hline 1. Enter 15 & $34 \%$ & $23 \%$ & $32 \%$ & $30 \%$ & $29 \%$ & $30 \%$ & $34 \%$ & $48 \%$ & $38 \%$ & $270=80 \%$ & $20 \% 450=100 \%$ \\
\hline 2. Prior 14 & $35 \%$ & $21 \%$ & $33 \%$ & $44 \%$ & $48 \%$ & $45 \%$ & $21 \%$ & $31 \%$ & $22 \%$ & $450=83 \%$ & $17 \% 540=100 \%$ \\
\hline Part $D$. & $a A r t$ & $b E n g$ & $c B o t h$ & $a A r t$ & bEng & $c B o t h$ & $a A r t$ & $b E n \Phi$ & $c B o t h$ & $a A r t$ & CTOT \\
\hline 1. Fast 1 & $15 \%$ & $4 \%$ & $9 \%$ & $19 \%$ & $19 \%$ & $19 \%$ & $66 \%$ & $78 \%$ & $72 \%$ & $27=50 \%$ & $50 \% \quad 54=100 \%$ \\
\hline 2. Norm 3 & $26 \%$ & $27 \%$ & $27 \%$ & $39 \%$ & $33 \%$ & $35 \%$ & $35 \%$ & $40 \%$ & $38 \%$ & $23=31 \%$ & $69 \% 75=1 \mathrm{co \%}$ \\
\hline 3. Stow 3 & $33 \%$ & $17 \%$ & $24 \%$ & $13 \%$ & $22 \%$ & $18 \%$ & $53 \%$ & $63 \%$ & $58 \%$ & $15=38 \%$ & $62 \% \quad 38=100 \%$ \\
\hline 4. All 5-hr & $2: 3 \%$ & $I^{\prime} q \%$ & $20 \%$ & $25 \%$ & $26 \%$ & $26 \%$ & $52 \%$ & $55 \%$ & $54 \%$ & $65=40 \%$ & $60 \%|67|=1.00 \%$ \\
\hline Part E. & $a A r t$ & $b E n g$ & $c B o t h$ & $a A r t$ & $b E n \sqsubseteq$ & cBoth & $a A r t$ & $b E n g$ & $c B o t h$ & $a A r t$ & $b E n \xi$ \\
\hline I..Fast 1 & $x$ & $x$ & $23 \%$ & $x$ & $x$ & $46 \%$ & $x$ & $x$ & $31 \%$ & $x$ & $x \quad 87=100 \%$ \\
\hline 2. Norm 3 & $x$ & $x$ & $20 \%$ & $x$ & $x$ & $45 \%$ & $x$ & $x$ & $35 \%$ & $x$ & $\times 228=100 \%$ \\
\hline 3. Stow 3 & $x$ & $x$ & $29 \%$ & $x$ & $x$ & $26 \%$ & $x$ & $x$ & $45 \%$ & $x$ & $\times \quad 38=100 \%$ \\
\hline 4. AlI $5-\mathrm{Hr}$ & $29 \%$ & $17 \%$ & $22 \%$ & $46 \%$ & $41 \%$ & $43 \%$ & $25 \%$ & $42 \%$ & $35 \%$ & $147=42 \%$ & $58 \% 353=100 \%$ \\
\hline
\end{tabular}




\section{CHAPTER 1 I.}

The amount of mathematics offered by ifferent groups of students for entrance to the University of Missouri. and some observations on the significance thereof: Introduction:

Leaving special studies in the field of secondary school instruction to the students of secondary school problems, we now proceed with the tabulation and discussion of the mathematics offered by different groups of students entering the University of Missouri at different times. The table facing this page is a condensed summary of data taken from different sources, this data being more fully explained and justified in the discussions of succeeding chapters. In this chapter we shall explain the general mechanism of the table, shall name the souroes of the data, and shall make some general observations upon the data. 1. Mechanism of TABLE NO. 111 .

This tablo shows the cercentages of students entering the University. at different times and in different groups, wfferingnts certain amounts of mathematics for entrance, these amounts being grouped thus:

Column I.Less 3 bnits, means the students offered Algebra and Plane Goometry only for entrance. A very small percentage offered Algobra only shee both were required. Column IJ.Just 3 Units, means the students offered Algebra, Plane and solid Geometry for entrance. In a few instances Higher Artthmetic or Trigonometry was offered instead of solid Geometry. Colum IIJ, Nore 3 Units, means the students offered Trigonometry (ar Higher Arithmetic) in addition to the above subjects for entrance. 
preceding

Column IV. Total Consideradshows the totals of the threed columns. The total numbers are shown in red, and from these totals the actual numbers in any column can be readily computed. The actual numbers only (not percentages) are shown in TABLE NO. $111^{*}$. (prec.page In the sub-columns ken refers to men students who are not Engineering students; Wom refers to women students; $\mathbb{E}$ ig refers to Engineering students; art refers to men and women arts students. In cotumns 1,11 , and 111 the sub-columns $c$ are the sums of the a and $b$ sub $\div$ columns. In column IV the sub-columns $a, b$ and $c$ are the sums, res rectively, of the $a, b, c$ sub-columns in $1,11,111$. The whole table is divided into five parts:

part A. In this part are considered all the students taking mathematics course 8 and logic course 1 in the first semester of this $(i 9 i 5-16)$ school year. The names of the students were furnished by the chairman of each department and the amount of mathematics offered for entrance was found from the entrance cards in the Registrar's offico.

Part B. In this part are considered the non-Engineoring students, mon and women; who entered the University in the Fall of $19 i 5$ (row i.) and who entered during the years prior to igl (row as far back as tho ontrance card records go, i.e. back to the year 1902. part c. This part corresponds to part B exactly except that hore we consider the non-Engineering (Arts from above Part B). and the Engineering students.

Part D. In this part are considered all the students who were taking the five-hour first year mathematics courses in the fall af: igit. In the sub-columns they are separated into non-Engineering(Art) 
and Engineering (Eng) groups. The three rows $1,2,3$, represent, respectively, the students in Course I (Elementary Analysis, the fast course), in Course 3 (Norm) (Irigonometry and Algebra, the normal section), and in course 3 (Slow) (Trigonometry and Algebra, the slow section). Row 4 is the total of rows 1,2 and 3 . The registrar's records were not avallable when this data was being collected, hence the students were asked to give the data regardind the amount of mathematics offered for entrance. This data was subsequently checked in part and was found to coincide with that found in the Registrar's office.

all the Part $E$. In this part are considered, students who took the fivehour irst year mathematics courses in certain years during the past seven years and who graduated from the University or are still in the University. Those students who took the courses and dropped out of school befcre graduation are not considered. The names of these students were secured from records in the Mathematics office, from the student directory and the atumni directory; the amount of mathematics offered by each.for entrance was then found from the entrance cards in the Registrar:s office.. The rows and sub columns of Part E correspond exactly to those of Part D.

An example or two in the use of Table No. 111 will. show its general use. (a) Suppose we are interested in the mathematics preparation of the students in Course 8 . We refer to Part $A$, row $i_{\text {.. }}$ Column 1, sub-column a shows that $30 \%$ of the 4.4 men taking the course had offered less than three units mathematics for entrance. $69 \%$ of the $16(60 \div 44)$ women in the class had offered less than 
3 units mathematics for entrance; and $40 \%$ of all the 60 men and women students in the class had offored loss than 3 units for ent trance. From column IV we learn that there were 44 men and 16 women in the course in the Fall of igi5. Thus the class was made up of $73 \%$ men and $27 \%$ women students. $69 \%$ of the women were required to take mathematics (or logic) having offered less than three units of mathematics for entrance (see catalog of Univ.). Only $30 \%$ of the men in the course, however, were required to take matrematics (or $\log i c$ ) for this reason. (The last statements are from column 1..) (b). Suppose we want to compare the amounts of mathematics offered for entrance by men and by women students. This can be observed in parts $A$ and $B$ rows $i$ and 2, by comparing sub-columns $a$ and $b$ in each of the first three columns. Thus, in the fall of $1915,36 \%$ of the men entering the University over agalnst $28 \%$ of the women had studied Trigonometry in the secondary schoolls. (From part B, row i, column 111 , comparing sub-cotumns $a$ and $b_{\text {.) }}$ ('studied Trigonometry'means 'offer more 3 11. Observations from TABLE NO. 111 .

The data of this table will be used krimarilly in support of the discussions of the following chapters. Parts of this condensed table will be elaborated and more fully explained. There ares however, some general observations which might best be made just here. These are noted under paragraphs numbered 1, 2. 1. Comparing rows 1 and 2 of Parts $B$ and $C$ we find in column 111 that the percentage of students who, offered irigonometry for entrance (more 3 units) is higher than the percentage of students who entered prior to igi4 (ice.igas, to igli4) and offered 
Trigonometry for entrance. Copying from Table Na. III, Part C, Columns $1 / 1$ and $I V$, we have the following table:

TABLE NO. IV.

Comparing kercentages of students offering more than three units for entrance in Fall of 1915 and $\mathrm{krtor}$ to 1914 (190\% to 1914).

STUDENTS:

i. Enter i is

2. Prior 'i4 offer more 3 units

$$
i 7 i=38 \%
$$

iig $=22 \%$
Total considered

$$
\begin{aligned}
& 450=100 \% \\
& 540=100 \%
\end{aligned}
$$

2. It is generally supposed that boys planning ENGINERRING work take more mathematics in the high school than do boys NOT planning Engineering work; also that BOYS in general take more mathematics in the high schools than do GIRLS. TABLE NO 111 enables us to test out this supposition for students who enter the University. Let us consider the students entering the University at different times and in different groups (Various parts and rows of Table 111) under these fou: heads: 1. Engineer, meaning Enqineering students; 2. Men Non-Eng, meaning non-Engineering men students; 3 . Womens, maning women students; and 4. Men \& Mom, meaning non-Engineering men students and women students: Let us now set up a new table from TABLE NO. 111 .

TABLE NO V.

Comparing amounts of mathematics offered for entrance by Engineering students, by non-Engineering men students, and by women students.

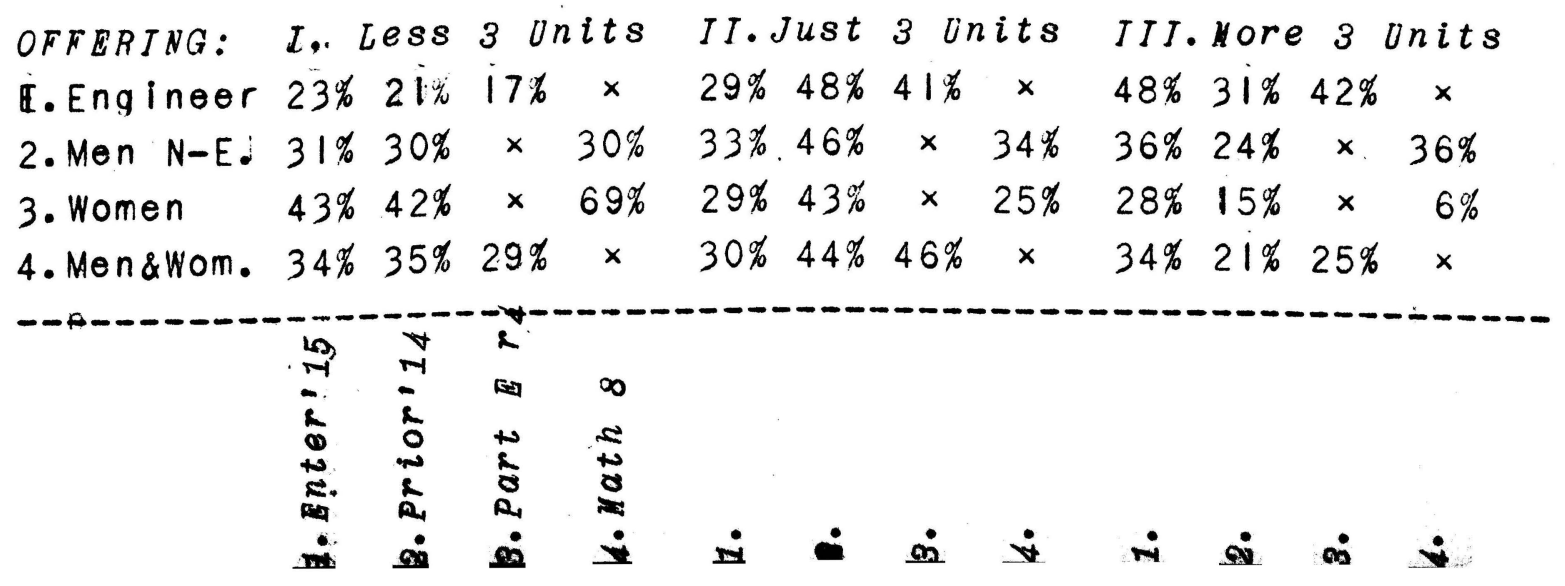


In using the above tabte, we make the comparisons verticallly. Thus in cotumn 1, first sub-column, we see that 238 of the Englneoring students offered liess than 3 units mathematics for entrance, whereas $43 \%$ of the women offered less than 3 units for entrance! In cotumn IIli, sub-column, we see that $48 \%$ of the Engineers offered offered more than 3 units, whereas but $28 \%$ of the women entering at a corresponding time affered more than 3 units. The first sub-columns are taken from part $C$ and part $B$. The second sub-columns are taken from ${ }_{A}$ parts $C$ and $B$. The third sub-columns are taken from row 4 of Part $E$. The fourth sub-columns are taken from row $I$ of part $A$.

In every one of these sub-coliumns we see that the Engineering students lead in amount of mathematics offered for entrance; non-Engineoring men students are next in amount of mathematics offered for entrancef and women students offer least mathematics for entrance. Thus our supposition is boene aut.

Here again is a problem for the students of high schoof mathematics courses and for the students of university mathematics courses: Shall we differentiate mathematics courses for amounts of mathematics required) for BOYS and for GIRLS and for boys planning ENGINEERING work?

Rèsumè of chapter 11 .

The above general observations from TABLE NO. 111 are minor in importance and significance. The fundamental purposes of the table will appear in the following chapters. 
CHAPTER 111 .

The actual form, content and purpose of the first year mathematics courses at the University of Missouri.

Introduction:

The mathematics department of the University of Missouri serves three rather non-clearly defined groups of students: viz. those students going into engineering work, for whom mathematics is a requirement; those students taking mathematics by free election, coming from every department of the University, some of them planning to go on into higher mathematics; and those students who, having offered less than three units entrance mathematics, are required to take at least three hours of mathematics or logic in the University. Some students of this third group may bevirtually members of the second.

The first year mathematics courses consist of three groups, or rather three different courses, one of which is made up of students separated into twa classes according to ability. Theso three courses are? General Mathematics, Gourse 8 , a one-semester, 3-hour course, meeting the mathematics-logic requirement mentioned abover Blementary Analysis, course 1, a onesemester 5-hour course in Algobra. Triganometry Analytic Geometry, followed in second semester by Callculus, the students boing picked students; Trigonometry and Algebra, Course 3, a one-semester, 5-hour course followed by Analytic Geometry in the second semester. Students in this course are divided into two sections, according to ability, thesexbeing known in this paper as Course 3 (Norm) and Courso 3 (SIow). In detall we have: 
1. General Mathematics, Course 8 .

This is, as stated, a 3-hour general mathematics course, best defined by the contents of the course as listed below: TABLES, of Squares, of Square Roots, cf Cubes; of Cube Roots, of Logarithms, cf Trigonometric Functions. These tables are used in solving problems of area and volume, problems involving long multiplications and divisions, problems of triangle solution, and problems of areas in general. The slide-rule is made the basis of the study of Logarithms..

GRAPHIC RE PRESENTATION, dealing with plotting tabulated (statistical) data and data given by a functional relation of two quantitios.

STATISTICAL TOPICS, including principles and uses of averages, chance, combinations, prabability, insurance, and scientific use and interpretation of statistics in general.

From the content of the course we see that it is of the 'practicat' or 'commercial' or rather 'citizenship' type. Tho course is primarily 'arithmetical' as distinguished from the 'goometrical' type. Students desiring more mathematics take Course 3 or Course 1 or (and Courses in Probability or (and) Business Mathematicsb

TABLE NO. III shows the previous mathematics training of the students in this course. The creparation, in extract the tablie on following page, is grouped as Less 3 Units and 3 or yore Ontts, meaning student is or is not required to take mathomatics (or logic) on account of the mathematics in entering. (From table No. III, part A, row 1). 
TABLE NO. VI.

Nathematics offered for entrance by WEN and by WONEN in Course 8.

OFFERING:

Men students

Women students

Men and Women
Less 3 Units

$$
13=30 \%
$$$$
11=69 \%
$$$$
24=40 \%
$$

3ior loteUnits

$31=70 \%$

$5=31 \%$

$36=60 \%$
Total in 8. $44=100 \%$

$16=100 \%$

$60=100 \%$

Thus we see that $60 \%$ of the students in this course are taking it by free election, boing froe from the University requirement. The remaining $40 \%$ are certainly required to take mathematics (or $\log i c$ ), yet some of these are also virtualty taking the course by choice as well as by requirement. 10 see also that most of the women in the class have not studied Solid Geometry (offered less than 3 units entrance mathematics). The course being, as stated, 'citizenship training' in nature, it is suited to, and of value to, any student. The question arises, however, as to whether or not this citizenship training course is best suited to that $40 \%$ of the class (including $69 \%$ of the women in the class) who have not studied Sollid Geometry in the High School!. Because they have not studied Solid Goometry, the University requires them to take mathematics or logic. Would it $n$ ot seem reas onable to moet the students' deficiency in Solid Geometry by means of a course more similar to solid Geometry than is course 8? The logic meets, apparentdy, one phase of the Solid Geometry, but not the real one, for the essence of Solid Geometry is not primarily 'logical'. but rather 'space perceptional'a in purpose and content. This phase of mathematics, Course 8 does not include. Discussionalater. 
11. Elementary Anallysis, Course 1.

All students desiring a 5-hour first year mathematics course enroll in course 3. After three weeks spent in review of Elementary Algebra, a written examination of one hour is given over this work. According to the grados made in this test, the students are separated into three groups: Those making the highest grades ( $32 \%$ of all) go into Course 1 ; those making the lowest grades go into courso 3 ( $S$ low), and the remaining ones ( $44 \%$ of all), go into course 3 (Norm).. Practicalty nothing other than the test in Elementary Algebra entered into the selection of the students for these three classes. Courses 3 (Norm) and 3 (slow) being the same type of course we shall discuss these under the general title of course 3 ; Course I shall be generally known as the Fast course, since it covers the topies of Algebra, Trigonometry and Analytic Goometry in one semestor, whereas course 3 requires a year for these three subjects. Ellementary Analysis, Course 1 , is followed in the second semester by The Calculus, Course 2, and these are followed in the next year by Differential Equations, Course 120. This suite meets the Engineering mathematics requirement. The students in this suite are, as stated, those standing highest in the Algebra test. The Analytic Geometry laps over into the second somester somewhat, and the groater part of the Integral Catw culus is done in connoction with the Differentiat Equations course in the next year. It is then the purpose of the fast suite to give to students in 16 hours of mathematics work these subjects: Trigonometry, Algobra, Analytic Goometry (5-hrs), 
The Calculus (5-hrs) and Differential Equations (6-hrs). The ordinary courses give to the students in 20 hours these subjects: Trigonometry and Algebra (5-hrs), Analytic Geometry (5-hrs), and Differential and Integral Calculus (10 hrs). This fast course suite, then, would seem to give to picked students in 16 hours work Differential Equationsa of the subjects covered by the other students in 20 hours work. But does the present organization of the courses produce all these desired results? In answering this, let us first observe more in detail the content and organization of the fast course suite:

The one-hour test on Elementary Algebra review work mentioned above as a basis for se rarating students into the three groups is certainly necessary but is not a sufficient test. It d ces not take into account the previous training of the students in mathematics: And in Course I the time allotment for each of the three subjects in the first semester is 80 limited that it is almost absolutely necessary to cut down the time for Trigonometry to about a week. This could well be dane, but for the fact that $28 \%$ of those put into the fast course (Falt 1915) had not previously studied Trigonometry. The presence of these students necessitated giving more time to Trigonometry than was needed for the remaining $72 \%$ who had previously studied Trigonometry. If, however, Trigonometry in the High School, be made a pre-requisite to course 1, then we could more efficiently apportion the time to the different subjects. The test alone leaves out all the PERSONAL olement in making the solection of students for the different courses. It is not 
known, in making the separation, what previous training the student has had; it is not known whether he be Arts or Engineer or Education or Agriculture; it is not known what further mathematics work he intends to take or is required to take; nathing is known of the student except his accomplishment or standing in Elementary Algobra at the end of three weoks review af this subject. This, then, is an evident weakness in the organization of course 1. Further reference to this and remedies for it, will be discussed in the fillowing chapter. Hore we merely point out the pacts.

In order to get an idea of the student's view of the fast courses, a questionaire was sent to all students now in the University who have taken one or more of the fast courses. Forty two of the ninety students to whom the questionaire was sent responded. The replies were unsigned thus increasing the probability of their representing the students' honest opinions. The question asked was this: "Are you satisfied, or do you regret, having taken the fast courses instead of the ordinary courses in corresponding years?"...... "Why?" ... Bolow are given some typical replies: ...." I am satisfied... I feel that to have spent a whole semester on Algebra and Trigonometry (ordinary courses) would have been time wasted. But for those who have n.ot had Trigonometry in High sichool, it might bo advisable that they take the ordinary courses"... Anothor reply runs thus:..." I regret it.... I might have majored in mathematics had I had a good thorough foundation in ordinary coursos... I had nothing past Plano Goomotry in 
preparatory school. I should advise only thcse students who have had Trigon cmetry or Analytic Geometry previously to try course I"... Still another: ..."I have always been sat isfled with the fast courses.... Time was left for advanced mathematics coursos"...

It is difficult to tabulate the digest of these repties. It was found, however, that $40 \%$ of the students answering the questionaire preferred the ordinary courses, the reason invariably given being the lack of preparation in Trigonometry and Geometry. Those preferring the fast courses did so on the basis of time being saved from the Trigonometry and Algebra for more advanced courses (Differential Equations).

The positive conclusions to be drawn from the questionaire are these: For students of inadequate mathematics preparation the fast course is not satisfactory, and for students of good preparation too much time is given to the Trigonometry, thus robbing the other subjects of time necessary for them. Most of the students quite distinctly appreciated the general plan of the fast courses, some, however, being almost bitter toward the plan of arbitrarily assigning students to the fast course, which they felt was not suited to their need.

As regards the content of Course 1, we might here note that three separate text books are used in the one semester's work: Rietz \& Crathorne Ccllege Algebra $(\$ 1.40)$, Kenyon \& Ingald Trigonometry $(\$ 1.35)$ and Ziwet \& Hopkins Analytic Goometry (\$1.60). Much of the material of the texts is necessarily o.mitted or differently treated. There can result only loss of time and 
energy in changing fram the notation of one text to that of another and in picking from a rather voluminous text only isolated topics. The number of different texts used and the appreciable cost thereof, wauld seem to point strongly to the need of a single text combining all these topics. The proposition of combination Texts will be discussed in the following chapters. (Cf. pages $9,34,44,52,55$, and 56).

111. Triqonometry and Alqebra, Course 3.

This course, as stated, is run in two types of sections, viz. the Normal section, made of the students making medium grades in the test, and the 'slow' section, made up of students making the lowest grades in the test. These courses are followed, in the second zemester, by Analytic Geometry, and in the second year by Differential and Integral Calculus. The topics covered in both sections are practically the same, the work differing mainly in intensity and number of exercises.

The content of the Algebra part of Course 3 is about that of a standard College Algebra course, omitting, however, such toples as: Complex Numbers, Horner's Method and Decartes' Rule of Signs, General Treatment of Logarithms, Limits and Infinito Serles, and Theory of Determinants. Some secial attention is given to Graphic'Approximation to Roots and to some of the probloms of Probability, Permutations, and Combinations.

The content of the Trigonometry is also about that of a standard Plane Trigonometry courso, topics omittod being: Trigonometric Trigonomotrte Equations, Imyorso: Functions, De Molvre's Thoorom, Complox Numbers, and topics of Analytic Trigonometry. 
Analytic Geometry, Course 4, follows Course 3, in the second semester. This is a standard course in Plane Analytic Geometry with two weeks spent on Sface Analytics. Determinants of Any Order and Complex Numbers are omitted. The text now in use includes some processes of the Calculus which, it seems, had best be left to the Calculus.

IV. Distribution and grades of students in first year courses. Numbers and percentages of Arts and of Engineering students in the various 5-hour first year courses,are shown below: (From records in the Mathematics Office).

Distribution of Arts and Engineers in first year 5-hr courses!

IN FIRST YEAR: Course I(F) Course $3(N)$ Course 3(S) All courses

$\begin{array}{lllll}\text { Arts students } & 26=33 \% & 37=47 \% & 15=20 \% & 78=100 \% \\ \text { Engineers } & 25=24 \% & 48=47 \% & 30=29 \% & 103=100 \% \\ \text { All students } & 51=28 \% & 85=47 \% & 45=25 \% & 181=100 \%\end{array}$

Thus we see that the percentage of all Arts students in course is higher than the peroentage of all Engineers in the course: in course $3(N)$ the percentages are the same; and in Course $3(S)$ there is a higher percentage of Engineering students. We should expect just this thing, since the Arts students are taking the course by free election whereas the Engineering students are all required to take the courses.

On the following page is tabulated the numbers and percentages of Arts and of Engineering students taking first semester 5-hour courses, who do take and who do not take the following second semester courses. (From records in Mathematics offico). 
TABLE NO. VIII.

Students in first semester and in corresponding second semester mathematics courses, separated as to Arts and Engineers.

$\begin{array}{llll}\text { TARING NATH: } & \text { First Sem } & \text { Sechd Sem } & \text { Drop Nath } \\ \text { Arts East 1. } & 26=100 \% & 16=62 \% & 10=38 \% \\ \text { Arts Norm 3. } & 37=100 \% & 16=43 \% & 21=57 \% \\ \text { Arts SIOw 3. } & 15=100 \% & 4=27 \% & 11=73 \% \\ \text { ALL ARTS } & 78=100 \% & 36=46 \% & 42=54 \% \\ \text { Engs Fast 1. } & 25=100 \% & 24=96 \% & 1=4 \% \\ \text { Engs Norm 3. } & 48=100 \% & 39=81 \% & 9=19 \% \\ \text { Engs SIOW 3. } 30=100 \% & 16=53 \% & 14=47 \% \\ \text { ALL ENGS } & 103=100 \% & 79=77 \% & 24=23 \%\end{array}$

Thus we see that but $46 \%$ of the Arts students taking the first semester mathematics courses continue with the following second semester caurses, whereas $77 \%$ of the Engineering students continue with the second semester courses. The Engineering students are supposed to go on with the second semester courses, those dropping out having ffalled out or left school. But not all the Arts students who dropped out of the mathematics courses fifilled t_--they merely did not elect mathematics the sec.nd semester. But what of it? The fact is, Arts $54 \%$ cf the students. who elect mathematics the first semester do not elect mathematics the second semester. This being the case, we naturally ask, are the one-semester mathematics courses taken by these students, the courses which, in the one semester only, give them the best mathematics training. This propasition will be discussed in the next chaptor. Here we merely point wut the facts, to which reference will be made later. 
Let us

observe now the distribution of GRADES among the three courses, Course 1, Course 3 ( $N$ orm), and Course 3 (Slow), Keeping in mind that Course 1 is made up of the (suppoeedly) best third of all 5-hr.. mathematics students; Course 3 (slow) is made up of the poorest fourth of all 5-hr. mathematics students: and Caurse 3 (Norm) is made up of the rest. (Records, Mathematics. TABLE NO. IX.

Distribution of grades among courses: Course 1, Courses $3(N) \& 3(S)$

GET GRADES: $\quad E \& S \quad H E \quad I \quad F \quad I \&$ Total

Arts Course $1 \quad 16=62 \% \quad 10=38 \% \quad 0=0 \% \quad 0=0 \% \quad 0=0 \% \quad 26=100 \%$

Engs Course $1 \quad 15=60 \% \quad 10=40 \% \quad 0=0 \% \quad 0=0 \% \quad 0=0 \% \quad 25=100 \%$

All Course $1 \quad 31=61 \% \quad 20=39 \% \quad 0=0 \% \quad 0=0 \% \quad 0=0 \% \quad 51=100 \%$

Arts Course $3(N) \quad 21=57 \% \quad 16=43 \% \quad 0=0 \% \quad 0=0 \% \quad 0=0 \% \quad 37=100 \%$

Engs Course $3(N) \quad 6=13 \% \quad 30=63 \% \quad 12=24 \% \quad 0=0 \% \quad 12=24 \% \quad 48=100 \%$

All Course $3(N) \quad 27 b 32 \% \quad 46=54 \% \quad 12=14 \% \quad 0=0 \% \quad 12=14 \% \quad 85=100 \%$

Arts Course $3(S) \quad 0=0 \% \quad 3=20 \% \quad 7=87 \% \quad 5=33 \% \quad 12=80 \% \quad 15=100 \%$

Engs Course $3(S) \quad 2=6 \% \quad 9=27 \% \quad 12=39 \% \quad 9=28 \% \quad 21=67 \% \quad 32=100 \%$

Alf Course (3S) $2=4 \% \quad 12=26 \% \quad 19=40 \% \quad 14=30 \% \quad 33=70 \% \quad 47=100 \%$

Total 5-hr Math. $60=33 \% \quad 78=43 \% \quad 31=17 \% \quad 14=7 \% \quad 45=24 \% 183=100 \%$

The pooling of grades of all 5-hour mathematics students agrees fairly closely with the normalized percentages, these being: E\&S to $25 \%$ of students; $M$ to $50 \%$; and I\&F to $25 \%$. the

We expect, from. frm of division of students, that those

in Course I will make highest grades and those in Course 3 (S) will make lowest grades. The effect of this 'predestining' of grados will be discussed later.

If, In the above table, we calculate percontages vertically, we get the percentages of each of five grades going to each $\operatorname{cours\theta }$. 
TABLE NO. $X$.

Number and percentage of $\mathbb{E} \&, N, I, F$, grades to each $5 ; h r$ course.

GRADES GIVEN: $\quad E \& S \quad N \quad I \quad F \quad I \& F \quad$ No.Students

Course I (F) $\quad 31=52 \% \quad 20=26 \% \quad 0=0 \% \quad 0=0 \% \quad 0=0 \% \quad 51=28 \%$

C curse $3(N) \quad 27=45 \% \quad 45=55 \% \quad 12=39 \% \quad 0=0 \% \quad 12=27 \% \quad 85=46 \%$

Course $3(S) \quad 2=3 \% \quad 12=15 \% \quad 19=61 \% \quad 14=1.00 \% \quad 33=73 \% \quad 47=26 \%$

All Grades $\quad 60=100 \quad 77=100 \quad 31=100 \quad 14=100 \quad 45=100 \% \quad 183$

Here again we see that Course $I(F)$ absorbed a big percentage of the E\&S grades, while to Course $3(S)$ fell the big percentage of I\&F grades. This theme will be discussed later. Rèsumè of Chapter 111 .

In resumè of this chapter, notice that the chapter contains tabulations of FACTS, definitions of ISSUES, and announcements of PROBLEMS, all relating to the study of the form, purpose, and organization of first year mathematics courses. In the next chapter these FACTS will be used in meeting ISSUES and in solving PROBLEMS raised in this study.

SOME EXTRA DATA:

The following data may be of interest to some, hence is given. TABLE NO. A. (From records in Mathematics. Grades in Calculus of Engineering and of Education raduates:

$\begin{array}{llll}\text { GET GRADES: } & \text { E'S } & M & \text { Total obser } \\ \text { Education Grad } 95=59 \% & 56=35 \% & 9=6 \% & 160=100 \% \\ \text { Engineer Grad } 146=29 \% & 280=56 \% & 75=15 \% & 500=100 \% \\ \text { Ed \& Eng Grad 241=37\%- } & 336=50 \% & 84=13 \% & 660=100 \%\end{array}$

BOTH Education and Engineer graduates thre above normal in number of E\&Siand below inaA\& grades students getabalacing I\&F grades? 
CHAPTER IV.

How the first year mathematics courses might be made to more fully realize their purposes, and, some additional purposes might be served by the present courses and by courses to be proposed.

Introduction:

Taking up the issues of the preceding chapter, we shall here more fully analyze and discuss the situations, shall propose and justify some positive recommendations for making the present courses more fully realize their purposes, shall proposes some modifications and extensions of these purposes, shall suggest some new mathematics courses, and shall discuss more fully the question of the form and content of the present and the proposed courses.

1. Regarding General Mathematics Courses:

As pointed out in the preceding chapter, there is an appreciable sized group of students now in General Mathematics Course 8, (half of whom are women), who, having not studied: Solid Geometry, are required to take mathematics or logic in the University. The most practicable course apen to these students is General Mathematics Course 8, a citizenship training typo of course. This course has a valuable and neoded purpose and is adequately fulfilling its purpose. It cannot, moreover, be materially changed without loss of efflciency. Hence in order to meet the apparent need of a Space Perception type of course, it seoms necessary to establish an entirely new caurse, co-ordi:nato with Course 8, this now course covering the more liberal 
field of Solid Geometry and including some elements of the Descriptive Geometry and any other subjects which will help to develop in the student the 'power of space visualization'. (Cf. paragraph regarding Solid Geometry in the Peking School, page 8, and also quotation from letter of Professar Roever, regarding value of Descriptive Geometry, page 54. ).

A course of this tyre would be cf value in itself, would be more in keoping with the spirit of the University requirement, and would relieve course 8 in its 'citizenship training' aspect of that cantingent of students desiring a different type of course. Some students now taking logic by University requirement might prefer this new mathematics course to the $\operatorname{logic}$

Administrative considerations need $n$ ot interfere with the scheduling of this new course. The three sections of course 8 scheduled for next year $(1916-13)$ could be replaced by two sections of the same type of Course 8 and one or two sections of the new course. Two sections awauld doursiliess be needed. for three sections of Course 8 are now scarcely adequate to acc modate the students desiring the course. Moreover, by relieving Course 8 of those students desiring a space type cf course, Course 8 itself could possibly draw more free election students to itself. Further discussion of the scheduling of these courses will occur later. This new course as proposed just here, shall be known as the proposed SPACE COURSE, abbreviated to Course (\$). Do not confuse with Course 3 (slow). 
11. Regarding selection of students for Course 1:

It was shown in the preceding chapter that the present method of selecting students for the fast course lets into the course students with no knowledge of Trigonometry. The attempt to give even the briefest course in this subject, robs the other subjects to be presented in the one semester of the time allotment necessary for them. A preqrequisite of Trigonometry for Course 1 would permit of: cutting down the time allotment for Trigonometry to a single weok of review, thus liberating two or more weeks for the other subjects. This Trigonometry pre-requisite would not cut out an undue number . of students from Course 1, since this year, without reference to pre-requisites, but $28 \%$ of those in the course had not studied Trigonametry previously. A mare careful and personal selection of students for the course would yield as large a class and as well prepared a class as does the present method of seloction by examination only. 111. Regarding TEXTS for course 1:

Course 1 at present uses three separate texts in the one semester's wcrk. The Trigonometry pre-requisite would all but eliminate the Trigonometry text, yet something for review and reference would still be necessary. Hence it would seem highly desirable to use in this course one of theyrecently published, or about to be published, combination texts combining. in a unified whole the subject matter of Algebra, Trigonometry and Analytic Geometry. Wider application of each of the subjects, better correlation, and avoidance of time loss would result. 
IV. Summary of present and oroposed plan of fast courses:

The present plan and proposed plan for the fast suite of caurses are given below in parallel column:

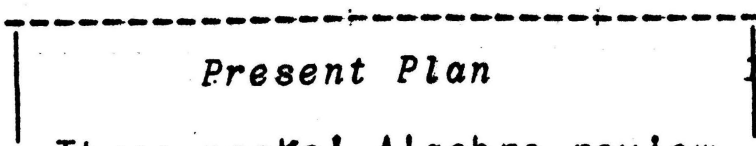

Three weeks" Algebra review, l-hour test, highest $28 \%$ go tp course I, no pre-requisite or rersonal element in selection.

Trigonometry given short time for $28 \%$ of class; inadequate for these and for others more than necessary.

Three separate texts in one semester's work. Continuity loss results.

Calculus second semester, Integral part running over in to next year. Poorer students drop to ordinary analytissat end of lst. semester.

Complete Calculus and Differential Equations 2ndd year Calculus-completed students enter begin lst. semester.

\section{Proposed Plan}

Same review and test, highest $35 \%$ with knowledge of Trlgonometry considered further for course 1. Personal element in selection.

Trigonometry pre-requisite permits of 1 -week review only, and saving time for other subjects.

Combination text, procuring correlation and preventing notation-change loss.

Completion of Analytics second semester. Then Differential and introduction to Integral Calculus. Poorer students drop to ardinary Calculus end Ist.sem.

Finish Calculus Ist. semester. Differential Equations proper in second semester. Completed-callculus students enter begin 2nd.sem.

the

The above summary shows a few simple alterations ina form and organization of Course 1 which, it seems, hould make the frast courses more fully realize thelr exceedingly worthy purposes. More af the personal element in the selectian of students for the course, and the use of a combination text in the first semester's work are the essential recommendations. 
V. Regardin one-semester mathematics courses for Arts students. Attention was called to the fact that $54 \%$ of the Arts, 1.e. all non-engineering, students who elected the first semester of five-hour mathematics, did not elect the corresponding or rather the following second semester mathematics courses. Those who dropped out of Course 1, dild so with the better preparation in mathematics, having to their credit three subjects instead of but $t w c$ as is the case where a student drops out at the end of the first semester of course 3. In case of those taking only Course 3 , it seems that this is not the best passible caurse. The student gets, in Algebra, little more than a review of good High School Algebra. In Trigonometry he gets the merest fundamentals off Plane Trigonometry, even this being review work far $45 \%$ of the students.

But what is to be done? Cne suggestion is this? Transfer to Course 8, general mathematics, those desiring only one semester of mathematics. If a student thus transforred has not had Sollid Geometry in the high school, ho might with profit take the proposed Space Gourse, in addition to 6.ourse 8. Administrative considerations need not prevent this as will be shown llater:

Another way of s.olving the problem is this: Explain more carefully in the catalogue and to the students in person, the exact nature and purpase of the first year courses, thus avolding some of the 'misfits'. There should be no difficulty in the way of having enough of the mathematics men in the office during registration wook to explain the courses to the students 
Perhaps the most satisfactary way of making the fivehour first semester mathematics course best suited to the neods of Non-Engineering students who take only the one semester of mathematics, is this: Establish a five-hour onesemester course, complete in itself, yet having a closely connected second semester sequel, the two semesters' work preparing adequately for the calculus. This course would run coordinate with the regular Course 3. This would mean, virtually, separating the Arts and Engineering students. This plan was in operation in the Mathematics Department of the University some ten years ago, the Arts course then being a three-hour Algobra and Trigonometry course in the first semester and a three-hour Analytics course in the sec cnd semester. The speed of this first semester course was about that of the present Coursol.. At that time only 12 of the 68 students taking the first semester work did not go on with the second semester work. Thus that time but $18 \%$ of the students ellecting the (Trigonometry and Algebra)

first semester mathematicsi did not elect the second semester Analytics course, whereas at present $54 \%$ of those electing the first (Trig.\& Alg.) Analytics semester course do not elect the second semesteracoursea. This is perhaps due to the technical difficulty at that time of not continuing a course through the year. For then the University coupses were on the rear basis, whereas now they are on the semester basis. The study of the relative value of the year basis plan and the semester basis plan for different courses woutd make a valuable study in itself. Here we meroly note tho facts regarding first year mathomatics courses. Under the year 
basis plan the greater part of the students starting with a first year 3-hour mathematics course got, in the YEAR (total of 6 hours), the three subjects, Algebra, Trigonometry and Analytic Geometry. Under the semester basis plan over half of the students starting with a first year 5-hour course get, in

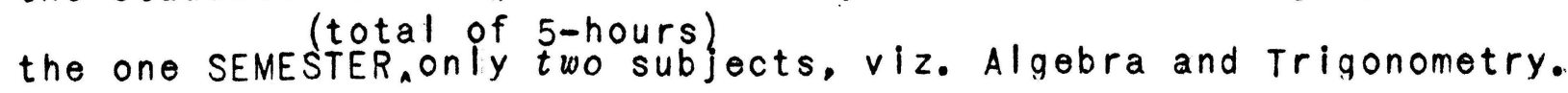
Thus, in 6 hours spread through the YEAR, the students got three different subjects, whereas, under the semester basis olan, the students get in the 5 hours of the one semester bat two different subjects. The final proposals concerning this matter will be shown up in better perspective at the close of this chapter $(p, 48)$. VI. Regarding segregation of students in first year mathematics. The students taking first year mathematics come into the courses with varied preparation and more varied needs and purposes. Evidently various types of first year courses are needed. each individual course being designed to meet the needs of a particuliar group of students. The working out of these various courses and the separation of the students for the courses has been receiving careful and persistent attention in the Department of Mathematics for several years. A large portion ef this study is concerned with this very same problem. The writer's plan of organization of first year courses calls for some wholly new courses, calls for certain re-adjustments in selection of students for various courses, calls for some changes in the content of the courses, and for expediency in making the re-adjustment, it calks for replacing certain courses with cheir peculliar organization by different courses with a different basis of organization! 
This last remark refers aarticutarly to course 3 (Norm) and course 3 (slow). The purposes of these courses the writer believes can best be fulfilled by means of a different selection of students and by different types of courses. We now proceed with the writer's criticisms of the princille of selection of students for these courses. The purpose of making the segregation aliways remains the same, viz. the best adjustment of instruction to the needs of the students through the medium of differentiated courses and differentiated grouping of students.

Referring to TABLE N@. IX, page 29, we find that 61 ix of the students in Course $i$ (Fast) received the grades E\&S: $54 \%$ of the students in Course 3 (Norm) received the grade $M$; and $70 \%$ of the students in course 3 (slow) received the grades 1\&F. (1st.sem. 15- 166) This is as we would expect from the plan of dividing the students into good, medium and poor groups for the threo courses mentioned. We seo that we have placed in the fast course (course 1) a group of good students, $61 \%$ of whom are to recoive the grades E\&S. In the slow section of course 3 we have a graup of poor students, 70\% of whom are to receive the grades 1 F. And in the normal section of course 3 we have a group of medium ability students, 54\% of whom are to receive the grade M. What effect will this grouping of students with virtually pre-determined grades have upon the actual work of the students in each group? The writer belleves that the actual accomplishment, regardless of grades, of the poor students will be less because of the tack of inspiration in the class given by better students and because of the p.resence of such a largo proportion of students unable ta do the work. 
The actual accomplishment of the good students will be less because the class

as a whole will tend to lag in eneray, knowina full well that the E's \& S's will be plentifut and the l's \& $F^{\prime}$ 's exceedingly sparse. Grant all the advantages of this type of seareation by way of araduation of content and conduct of the class to the ability of the students, yet the osychological effects in this seareation will outweiah all other considerations. A to be defeated by the method used for getting the results principle of recognized merit seems. The whole question is desired. very much a matter of personal obinion and observation of the actual effects on the students thenselves.

The real solution of the problem lies, perhaps, not in seareation or non-seareqation into sood, medium, and poor sections of practically the same course, but the solution lies, perhaps, in establishina different courses, and then put into these courses the students, sood, medium and poor in ility, according to the fitness of the student for the particular course recommended for him. This again will be fully outlined and discussed in later paraarans..

V11. Reaardina the need for a Preoaration Course:

Referrina to TABLE NO. 111, awe'find that $26 \%$ of the students

in Courses 3 (Norm) and 3 (Stow) in have not studied Solid Geometry in the high school (i.e. offered less than 3 units entrance math.). The very fact, moreover, of the establishment of the slow section of Course 3 confesses the inability of the students in this section to do standard elementary Triaonometry and Colleae Alqebra work. Also we saw that $70 \%$ of the l's \& F's qiven to the 5 -hour mathematics students went to students in this Slow section(2 sections) of course 3. From these facts we can but 
conclude that there is an aporeciable sized group of students taking first year mathematics who are not doing satisfactorily the most elementary standard Trigononetry and Colleae Algebra wark. What can be done? One solution is, to let things stand as they are, the students not being able to do the work in Course 3 (stow) being automatically and in due time elliminated from mathematics. But we. must keep in mind that elimination from 5-hour mathematics course carries with it a strong possibillity of the ellimination of the student from the University; for failure in 6 or 7 hours work means dismissal from the University entirely. Another possible solution is this: Estabtish a PREPARATION COURSE in mathematics for students who, for any reason, promise to be not able to make a grade in a fully standard Triaonometry and College Alaebra course. Let this Preparation ourse be what the name sianifies-i-a course desianed to prepare an inadequately prepared, or a poor ability, or a lazy, indifferent, student to make a arade in a fully standard 5-hour course when once he is admitted to such a course as Course 3 (Standard). To the inadequately prepared student such a course would give that preparation which would enable him to compete un-handicapoed with the better prepared students in Course 3 (Standard). To the poor ability student such a caurse would qive added prebaration and increased confidence which would put him in a better position to make good in the Standard Course 3 if he must take it. And to the lazy student this course would allow no shadow of doubt as to the justico of his efimination in case he faits in this or later 
The mere proposal of this Preparation Course put us at the very core of the question now before the University, viz. the question of the division line between university courses and high school courses. Bcth universitiesand secondary schools now aive first courses in German, French, Greek, History, Physics, Chemistry, Domestic Science, Advanced Algebra, Trigonometry, etc, etc. The University of Nissouri has just thrown open its various departments to students offerina alnost any combination of subjects, studied in an aparoved high school course of four years. Hence next year, or surely the next, students may be exoected to enter the University with no knowledge of mathematies beyond elementary sehool Arithmeticthe University admits these students to, say, the Enaineering Department (virtually does so, if not technically). The Enaineering department then reauires of its students for araduation a knowledae of mathematics including the Calculus. The most elementary course offered these would-be Enaineers, is Advanced Algebra and Triaonometry in Course 3. Evidentlly mathematics courses between alementary school Arithmetic and Colleqe Alqebra are, or soon will be, needed.

Combining then the present need of a Preparation Course for poorly prepared and poor ability suadents, with the near futuce need for an intermediate course, we have a doubled necessity far the establishment of the proposed Prevaration Course.

The Administrative situation to be met is this: The searegation of students into food, medium and poor aroups for 
Courses 1 (Fast), 3 (Norm) and 3 (Slow), $O R$ the proposed separation of students for the three distinct courses, viz., Course 1 (Fast), Course 3 (Standard) and the Preparation Course, demands that a suite of these three courses be run at each of two morning hours, with overflow sections of Course 3 (Undivided) in the afternoon. The only administrative difficulty in the way of establishing this Preparation Course might be because of an insufficient number of students for fllling two sections of the course. This difficulty, however, is met in this way: Make the Preparation Course a three-hour courseThis in itself is gaod, in that it automatically reduces the number of hours on the weak student's schedule- Then schedule the three-hour courses, Course 8, the proposed space Course, and the ..Peparation Course, all at the same hour with the five-hour courses. The schedule of the three-hour courses be might, arranged thus:

TABLE NO. B.

Day schedule of three 3-hour first year Mathematics courses.

\begin{tabular}{lcccccc} 
ON THE DAYS: Mon & The & Wed & Thu & Fri & Sat \\
At Ist.Morn Hr. $8 \& P$ & $S$ & $8 \& P$ & $S$ & $8 \& P$ & $S$ \\
At 2nd.Morn Hr. S & $8 \& P$ & $S$ & $8 \& P$ & $S$ & $8 \& P$ \\
At Both Hrs. $\quad 1 \& 3$ & $1 \& 3$ & $1 \& 3$ & $1 \& 3$ & $1 \& 3$ & $\ldots$ \\
\hline
\end{tabular}

"8" above means Course 8, General Mathematics. "P" above means the proposed Preparation Course. "S" above means the proposed Space Perception course. "I" above means Course 1, Elementary Analysis. "3" above means Course 3. Trigonometry and Algebra, this course, shown later, to be divided into "Arts" and "Eng" sections. 
The above scheduling permits a Preparation Course student, by increasing his schedule by but one hour, to get the space Course on the day-hours liberated from his original schedule by changing from his scheduled 5-hour mathematics course 3 to the Preparation Course ( $3-h r$ course). Also, a student desiring both Course 8 and the Space Course, could get both these courses in at the same hour of the day, running all six days. Again, a student found not suited for Course 8 , could be readily transferred to the Preparation Course reciting at the same hour. The above scheduling calls for ten sections of mathematics (first year) in the morning. The kresent schedule (1916-17) calls for nine corresponding sections, there being one less 3-hour section. With the new courses proposed, enough new students will come in to fill this one extra section. A fuller outline of the scheduling will be found at the end of this chapter. Here we note that the proposition regarding the filling up of the Preparation Course is satisfied by making the Preparation Course a 3 -hour course, thus bringing into it the misfit students of Course 8 , and perhaps some students who atherwise would choose logic in preference to Course 8 for meeting the University mathematics-logic requirement. VIII. Reqarding Segregation of Arts and Engineerina students.

In section $V$ of this chapter it was shown that the present Course 3 is not the best 5 -hour course for those students who do not go on with the second semester's work. Administrative considerations make the establishment of a special course for these students impracticable (even if it were known before- 
hand which students would nct go on with the second semester work). It is, however, possible to divide the Arts and Engineers in the two sections of Course 3 (Standard) at each of the two morning hours, filling up the Arts sections with Engineers if need be for balance. We would then have two courses, viz. Course 3 (Arts) and Course 3 (Eng). As subject matter for this Course 3 (Arts), use one of the combination Texts, dividing the material included in such a text into two parts, such that the one semester's work would give the student a greater variety of topics and more valuable topics than he now gets from the one semester's 5-hour Trigonometry and Algebra course; and dividing the material so that there would be offered to the student a strong incentive to continue the work into the second semester. The course could be a complete one-semester course, yet having a smoothly connected second semester sequel, which would draw the student on to the completion of the year's work. The year's work would prepare adequately for the Calculus. But this same combination Text scheme has been, or will be, proposed for the reqular Course 3 (Standard), regardless of whether students be Arts or Engineers, hence the need of the separation of Arts students into a special class would seem to be obviated. This brings us, however, to the bigger and more essential proposition, namely that of the general principle of segregation of Arts and Engineers in mathematics. This proposition we shall here proceed to discuss.

Separation of the two types of students makes possible greater specialization for each, and permits a closer follow- 
ing of the interests of each group. Non-separation fosters mutual broadening, each group coming in contact with the viewpoints of the other. But in first year mathematics groups, there are not present distinctly Arts and distinctly Engineering view-points, by conjunction of which mutual broadening might result. The students in first year courses have not yet developed Department view-points and basic interests in mathematics, in or any other subject, in fact. Hence it would seem best to separate Arts and Engineering students in the first year courses in order to allow the distinct view-points to develop and take form, and then in the second year put the Arts and Engineering students together, for the purpose of this mutual broadening through contact of the two view-points. The attutude of the Engineering student and the attitude of the Non-Engineering student towards mathematics, are distinctly different--and rightly so. The Engineering student in mathematics should never lose sight of the fact that he is an Engineering student, nor should the Non-Engineering student in mathematics fail to realize that he is not an Engineering student. Hence in first year mathematics courses we should foster the Engineering and the Non-Engineering view-points separately, combining these in the second year courses for the purpose of broadening the view-points and purposes and methods of both Engineer and Non-Engineer. Hence the separation of Arts and Engineers in Course 3 is proposed. Administrative considerations prevent separation in Course I (Fast), even were it desired. 
1x. Regardina the factors at work in producina possible chanaes in the content and intensity of first year mathematics courses. During the past few years several changes have taken place in the organizating of the University as a whole and in the organization of the mathematics courses. Some of these changes might very well tend to bring about improvement (or possibly deterioration) in the content and intensity of the first year mathematics courses. For this reason some of these changes are listed here in the hope that their effects may be further investiqated.

1. Frevious preparation of students c cming into the mathematics courses.

2. Introduction of a ranking grading system.

3. Change in the University from the YEAR basis to the SEMESTER * basis.

4. Elimination of separate mathematics courses for Arts and Engineering students.

5. Introduction of the fast course suite, and of two sections of course 3, the material in the two sections being very similar, the sections differing essentially in respect to ability of the students. 6. Intraduction of a series of text books embodying, to a certain extent, certain pedagogical principles.

Some of these propositions, not in exactly the form stated here, are discussed somewhat in this study. All of the policies of the University and of the Department of Mathematics listed above tend to bring about improvement or deterioration in the first year mathematics courses. For this reason further study is suggested. 
X. Reaardina the oroblem reader system.

It is not the intention of this study to go into the fine details of class conduct, teaching plans. The proposition, though, af problem reading is, from the standpoint of the problem $r$ eaders at least, of some interest. The problems handed in daily by students in first and second year mathematics courses are checked and recorded by student problem readers. These positions pay only scantily for the actual time spent in going over the note books. Both Engineering and Arts students, who did good work in mathematics courses, are employed in this work.

It would seem advisable to put this work on a basis other than that of

the financial recompense only. It might be put on a sort of scholarship basis, Education students planning to teach mathematics being employed for the work. This problem reading work would be excellent training for these readers. The writer values very highly his experience as a problem reader in Mathematics while an undergraduate student. An Education student reader could, moreover, affard to spend time in getting in closer touch with the class work. This would of practical use to bcth the reader and to the instructor of the class.

The problem reading for the correspondence courses in mathematics has been put on a basis similar to the one just proposed $f$ or the problem reading in first and second year University mathematics courses. The educational value of the problem reading (to an Education student) wculd make the position desirable and would secure more attention and time for the actual money expended. 
XI. Comparing the present organization of first year mathematics with the proposed organization.

By present organization we shall here mean the courses as scheduled for the 19i6-17 sch ool year. The purpose of this summary is to show the nature and scheduling of the proposed courses, and to show how the present organization and scheduling of courses can be made, by slight alterations, to accomodate the proposed organization and scheduling.

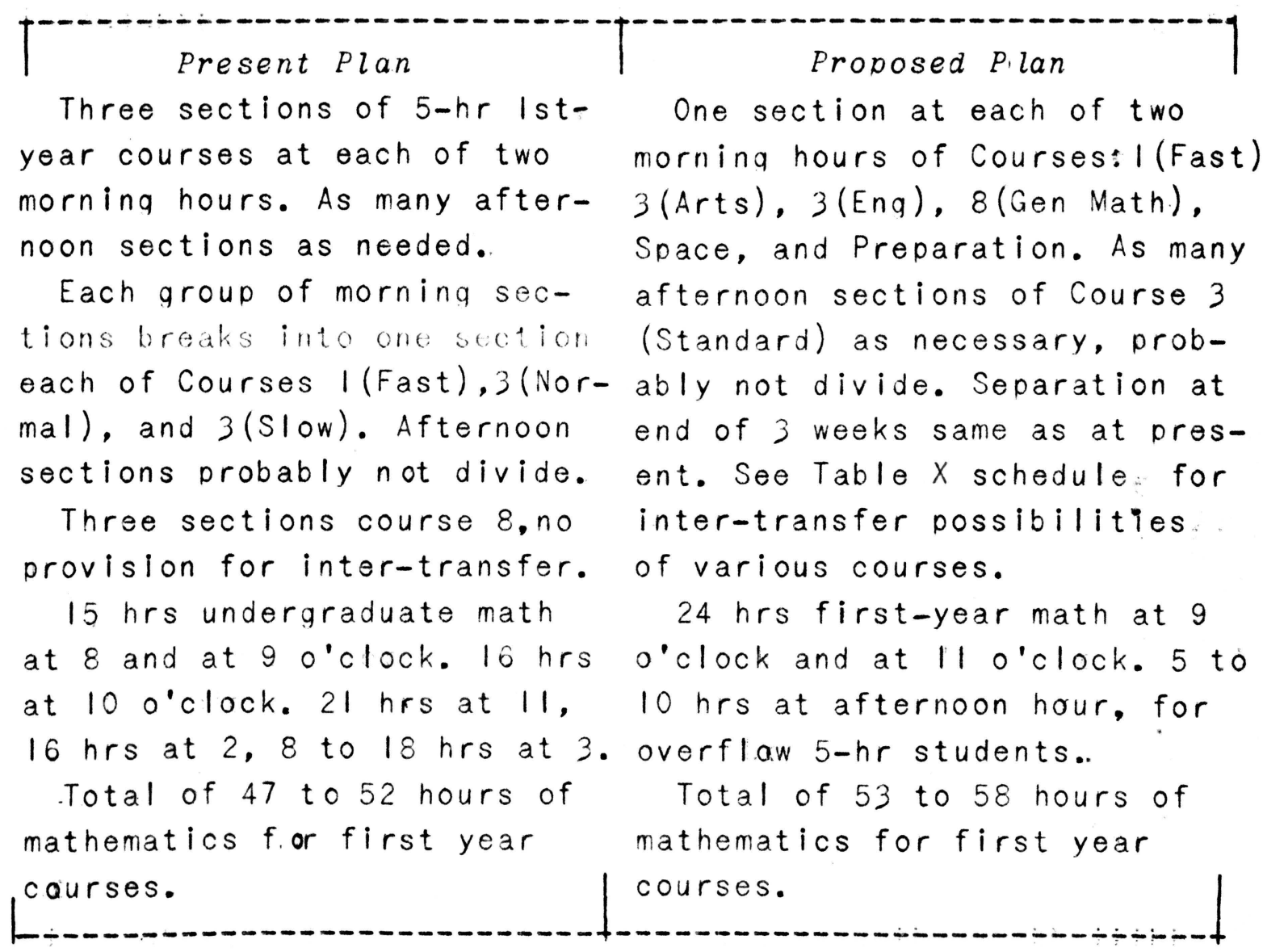

Thus we have before us not only the proposal of what would seem ta be a very servicable set of first year mathematics courses, bat we also have the corresponding possible scheduling of these courses, this scheduling not at all outreaching the administrative possibilities. 
Rósumé of Chapter IV.

It is not at all the purpose or intention of this study to offer suggestions to the Department of Mathematics as such, relative to the organization of courses for that Department. The actual situation in a representative university is used in order give material form and an efficiency test to the general principles and propositions set forth in the study. The argument of the study becomes of concern when it is shown to be capable of being put into actual operation through the agency of the actual machinery of an actual institution. The Academic principles underlying this particular and local study will be enunciated and discussed somewhat in the following chapter. 
CHAPTER V.

A resume of the general principles involved, and the conclusions to be drawn from this study.

Introduction:

The discussions of this paper thus far have centered closeIy about the first year mathematics courses at the University of Missouri, even taking note of the last detail of putting the suggestions into operation through the actual existing administrative machinery. The analyses and propositions have, however, been based first and fundamentally on educational principles, the administrative considerations serving as a practicability test. The study thus far seems local and particular, yet there stand out some general principles a enhanced.by the fact that they can be put into actual operation. The contribution of this study, as manifested in the discussions of the preceding chapters, consists the discussions : of the above mentioned courses with the purpose, form, content and organization suggested for them.. A particular situation has been analysed. It has been shown wherein certain first year mathematics courses do meet the situation, and wherein certain courses do not meet the situation, In the latter instances we propoşed the form of courses which shouldmeet the situation. Let us here, then, recall and restate some of the general educational principles underlying and fundamentally directing this study. 1. The field of first year mathematics and the types of courses needain this field.

There is throughout the United States a growing tendency and necessity for the universities to teach anything anyone 
might care to learn. In mathematics this means the tendency and necessity of teaching to maturer students those subjects generally considered as belonging essentially in the second:ary schools. The local solution for meeting this situation lay in the three proposed 3-hour, one-semester, first year courses, viz. General Mathematics, Course 8, a citizenship training type of course; Preparation Course, for those students not able or prepared to do standard Trigonometry and College Algebra work; Space Perception Course, designed to give a more liberal space training than is usually given in a high school Solid Geometry course.

One or all of these courses, perhaps, should be taken by every university student who has not previously received the equivalent training. This is the least mathematical training and equipment with which a university student should presume to meet his obligations to society. Quantitative thinking is essential to intelligent citizenship. And this is the service of mathematics---not primarily service to the individual for his individual needs---but service to society through trained citizens.

The technical presentation, of mathematics, pre-supposing the ideals and information mentioned above, demandsathe courses be so organized as to give the most adequate andefficient service. Algebra, Trigonometry and Analytic Geometry are the courses usually included in the first year mathematics work. For specially prepared students, Calculus is sometimes taken up in the first year's work. The question of the best form for pre- 
senting these subjects is well worth considering. The local solution of this proposition, discussed in preceding chapters, lay in the proposed suite of 5-hour first year courses: 1. Elementary Analysis, Course I (Fast), for students of special mathematics preparation and exceptional ability, covering in one semester the essential material and processes of Algebra, Trigonometry (review and orientation) and Analytic Geometry, this course serving for both Arts and Engineering students. The second semester would then include a good half of the Calculus, the year's work to be followed by a 3-hour course running through the next year, completing the Calculus and Elementary Differential Equations and Applications.

2. Course 3, Trigonometry and Algebra and possibly some Analytic Geometry, for ARTS students, in the first semester, and the completion of this in the second semester. This course would have practically the same material as is covered in the first semester of the Elementary Analysis course described above, more. time being required on account of the students not having as extensive mathematics preparation as have the above students. A combination text is recommended so that a single semester of this course might give the student greater variety and more useful material than is found in the one semester of Algebra and Trigonometry alone.

3. Course 3, Trigonometry and Algebra, for ENGINEERING students, the same general type of course as the above, the students here being Engineering students. This separation of Arts and Engineering students will be summarized in later paragraphs. 
The two groups of mathematics courses described above, each representing a fundamental phase of mathematisc, point out to us at least two fundamental tendencies in the field of mathematics. The one is the humanizing of mathematics, typified by the citizenship training and the space perception types of courses now existing or herein proposed. These are the result of ..... "a certain unrest and tendency toward investigation of the purpose and meaning of the subject matter that we teach and its relation to the life of the community. There has been a change from the older scholastic attitude throughout our colleges toward a more critical attitude regarding the usefulness and the ultimate justification of our instruction. This does not imply an attitude of commercialism or utilitarianism, but only a purely scientific inquiry into the grounds for giving in:struction with respect to the larger divisions of knowledge and with respect to the minor topics in each subject". *

A second fundamental tendency in mathematics and in educational discussion in general, indicated in the above quotation, lies in the examination of the actual topics and processes of mathematics courses most suitable for the mathematical training of different students......" In so far as the purely pedagogical questions are concerned, many have labored and are laboring to solve these questions. With respect to those more technical questions which involve a professional knowledge of the particular subject, however, only those trained in that subject could be expected to solve the problems or even to fully comprehend them"." Here we shall mention but one such topic,viz. *E.R.Hedrick in School and Society, 
Descriptive Geometry. Is it a course valuable only to Engineers and as such to be kept a technical, frofessional subject in a professional Department, or is it a subject of more than professional, engineering concern? If it is fundamentally and exclusively a professional,engineering subject, then it daes rightfully belong exclusively in the Engineering Department. But is the subject, by its very nature, strictly limited in its service to the engineering profession and practice? Mathematics men at Washington University are interested in a movement toward putting Descriptive Geometry in some of its various farms into a field not wholly restricted to the engineering profession. In answer to a request of these men for a discussion of this proposition, Professor Roever says this:.... Now the object of Descriptive Geometry is to represent_space objects by corresponding plane figures in such a way that the correspondence is unique and unambiquous...... Certain branches af Descriptive Geometry enable us to make pictures which help to develop the power of space visualization, and this power, as every mathematician knows, is a great asset at least in certain branches of mathematics. An examination of the books on Pure and Applied Mathematics shows clearly that the authors of mathematical works pay very little attention to the proper drawing of figures."...... From the standpoint of mathematics per se, it would seem, from the above, that Descriptive Geometry is of some importance to other than Engineering students. The teachers of all space subjects should possess a goad knowledge of Descriptive Geometry. But 
this again is a proposition on the border of the field of this study. The Mathematical Training of Teachers of Mathematics is a subject well wothy of further study. The "American Mathematical Monthly" has called for a symposium on this very question. (See March 1916 issue of the "American Mathematical Monthly".) 11. Regarding text books for first year mathematics courses, and their essential characteristics.

This study is not concerned with any particular text or texts for first year mathematics courses. But it is concerned with some of the general principles involved in, and represented by, various texts for various courses. As has al ready been pointed out, any multiciplicity in number of texts used in a given course, means a corresponding multiciplicity in terminology and a consequent diffusion of energies and dissipation of continuity. The writer has just read the manuscript of a Combination Text for first year mathematics, about to go to press; also a text of the same general type, recently published, has been carefully and critically examined. Two or three more such texts are well under way of preparation. All these typify a distinct movement in the field of first year collegiate mathematics. This whote movement represents the mature effort of men standing high in the profession of constructive, scientific, mathematical progress. These texts represent, in their field, the spirit of careful, scientific, educational activity, founded on and demanding a professional knowledge of the subject under consideration..

Relative to the actual working of a first year mathematics 
course using a Combination Text, Professor slichter of Wisin a personal letter to the writer, consinmsays this:.... "The Elementary Analysis (combination text) is taught to all first year Engineering students at Wis consin. We spend about two weeks in a review of high school Algebra, after which we give a written examination in Algebra. Those students that show that they need more work in Algebra (about 20\%) are given that work in regular classes, and the rest go ahead with the text in Elementary Analysis. We are much pleased with the results. We feel that much time is gained, that the students take a greater interest in their work, and that a more scientific attitude and poise is attained by them, compared to the results of routine courses of the usual freshman type"....... This is quoted not as the personal views of a certain person, but as expressing happily the claims of all combination Texts and of all courses based on them. This raises the question of the method of procedure in the presentation of any subject. A combination text represents somewhat the idea of working from the more general proposition toward the specific details, whereas the separate course texts represent somewhat the idea of working toward the more general propositions from the specific details scientifically and logically presented. This again is a general pedaqogical proposition, demanding a prossional knowledge of the subject under sonsideration.

In the foregoing discussion, the writer's idea of a combination text calls for a real unified course, not a mere 'tandem' affair of three subjects in a single binding. 
111. Regarding segregation of students.

Segregation of students or separation of students into various groups for various purposes is a princiole applied in all phases of Administrative Educational Problems. As regards first year mathematics, the local considerations in the preceding chapters led to this:

1. One type of segregation is made an the basis of ability of the students, the courses being then somewhat modified in content and conduct according to the quality of the student group put into the different courses. The principle proposed by the writer in this study is not a segregation on the basis of ability alone with the consequent unfortunate results point; ed out, but rather a separation of students called for by establishing different courses into which students are directed according to the fitness of the student for the course and the suitability of the caurse for the needs of the student. Fundamentally distinct courses are established, and students of all abilities are directed into the course for which they are best prepared and which are mathematically best suited to the needs and purposes of the students, Jegregation on tike basis of ability alone places the students who are most likely to NOT succeed in a given course into that course. It also groups the students most likely to do exceptionally good work in a given course into that course. The writer's criticism of thisis scheme is based an his that its psychological effects tend to recure in an actual intellectual accomplishment on the part of the students which is less extensive and intensive than 
that which might be attained by the different principle of separate courses. The proposed separation sets up standard, aistinct courses, open to all studentsto whom the courses are considered best suited. On this basis it is maintained that each student is served by a course properly graduated to his needs and purposes, and that he will get most actual mathematical knowledge out of the course. In any event, the actual grades given, evedently, under a ranking grading system, will always be the same.

The proposition of separating ARTS and ENGINEERING students was quite generally discussed in the preceding $t$ chapters. The conclusion was this: Separate Arts and Engineering students in the first year courses in order to foster the development of the two view-points; then in the second year put them together for mutual broadening and vitalizing of view-points and purposes.

At a round-table discussion of the proposition of different mathematics courses for Arts and f.cr Engineering students, various well known mathematics men present made the following remarks, in substance: (From the writer's notes taken at this ing). "Same work for all (Arts and Engineering) students". "Profess or -.--'s Elementary Analysis for Engineers; Arts take mathematics pure and unadulterated". "Messrs. - - and -- - are making a general mathematics book". "Mathematics for all that will prepare for higher courses". Thus we see that opinion was divided on this question, the administrative considerations perhaps controlling partly. 
Rèsumè of orientation of this study and of further studies. Cnly within recent years, and in fact, within recent months, have the undergraduate university mathematics courses been receiving effectually organized attention. One of the early activities in this field was the presidential address of P. ro- p. i02. (published in the Bulletin of the American Mathematical Society, fessor E. H. Moore abefore the American Mathematical Society in the 1902 meeting. The names of Perry and Borel and Klein are connected with like movements in England and France and Germany. Another indication of desired activity in this field was the joint meeting of mathematicians and engineers at Chicago in 1907. The re-organization of the "American Mathematical Monthly" for the purpose of meeting the needs of the collegiate mathematics field, marks, perhaps, the most effective efforts in this field. The partial fruition of the efforts of the men back of this journal is found in the organization of the "Mathematical Association of America". (Organized January 1916). This organization stands for 'mathematical research' in the broader sense of the word 'research'. This study has been encouraged, inspired and colored by the ideals and frinciptes for which the Association stands. As a member of the Association, with field of work in China, the writer feels an added responsibility attached to his work in the Poking school--.-not only as concerns the mathematics work in this particular school, but also as concerns the proposition of having a part in helping to formulate and organize the mathematics work in all the schools of China. Herein lies a large field for study and activity. The field is comparatively fallow, and upon those 
now engaged in establishing a mathematics system therein, rests the responsibility of the efficiency of the system established, and the responsibility of the 'traditions' set up for mathematics in the whole school system of the country.

The public elementary schools, imtermediate schools, high schools, colleges, technical schools and universities of China are just now in process of re-crganization along lines of the best things in the educational systems of America and Europe. Western subjects are being put into the schools along with the best portions of the older Chinese subjects. American text books of History and Science and Mathematics are being translated directly into Chinese; also, these American texts are being re-edited both in English and in Chinese, to suit the needs of the Chinese schools; and some texts are being written entirely for the Chinese schools, both in English and in Chinese. All this denands many new words and definitions in the language, the Chinese lanquage not lending itself readily to expressing scientific ideas in scientific terminology. A great deal of progress has been made in the way of developing a Medical terminology and literature. Work of this nature in all the sciences and in mathematics is much needed. As stated before, the field is fallow, and America should have a part in the work.

It is in this field of mathematics and education that the writer purposes to continue this study and carry on mathematical research in some of its many professional and educational phaseso 


\section{BIBLIOGRAPHY AND OTHER SOURCES OF INFORMATION:}

This study is experimental and statistical in nature, hence it has a peculiar bibliography. The articles bearing on this subject which were not consulted are manked $(*$ ). 1. Books. Various high school mathematics text books of the different types. First year university mathematics text books consisting of: a. Several standard texts such as Rothrock's Trigonometry, Kenyon and Ingold Trigonometry, Fite's College Algebra, etc, etc. b. Two combination texts for first year university mathematics courses, viz. Slichter's Elementary Analysis, and the manuscriot of a combination text about to go to press. Missouri Public school Report for 1914 and for 1915. Yule's text book on Statistics and Probabilities. Descriptive Geometry text books, books on the Psychology of Space Percetion, and various psychologicat and pedagogical discussions of mathematics.

Catalogs of the University of Missouri and of various other colleges and universities.

Foreign mathematics text books and school catalogs. Easy Niathematics by Sir Oliver Lodge.* Several combination texts in preparation.* 
11. Vaqazines and publications.

The American Mathematical vonthly, all issues since isiz. especially the latter issues of 1915 and the January, February, March and April issues of igi6.

School science and Nathematics, (a monthly journal dealing with secondary school mathematics and sciences), all issues since i909. School and society, article by professcr E.R.Hedrick in issue. Bulletin of The American Mathematical Society. igis and igi6. Student and faculty publications of Tsing Hua College at Peking China. Nagazine articles read or discussed in a seminar course in current Problems, (Dr.Pyle, Fall 19i5). 
111. Other sources of information.

correspondence relative to the organization and purposes of the

Mathematical Association of America, in the hands of professor

E.R.Hedrick, first president of the Asscciation.

Correspondence of the writer with professors of mathematics in

various universities and colleges.

Neetings attended by the writer this $(19 i 5-16)$ school year:

a. The American Mathematical society, in st. Louis, November igi5.

b.Call meeting for discussing the proposition of organizing a

new mathematical association (Nathematical Association of America in preliminary form

was temporarly organized), in St. Louis, November igis.

c.Conference of college Teachers of Nathematics, in St. Louis, November igi5.

d.Conference of Superintendebts and Principals, High School Day, igí. Manuscript submitted for publication in the American Nathematical

Monthly which has not yet been published.

Records in the Registrar's office.

Records of the Department of Nathematics----courses given at

various times, grades of students, etc.

Work as head of the mathematics department in a high school of

vissouri, in a college of Missouri, and in a college of Chína. to igis

Work as an assistant in mathematics at the University of Nissouri

igi5-i6 and as a problem reader in mathematics in igo8-09

and $i 909-i 0$. 


\section{Columbia Missouri \\ Nay II, I9I6.}

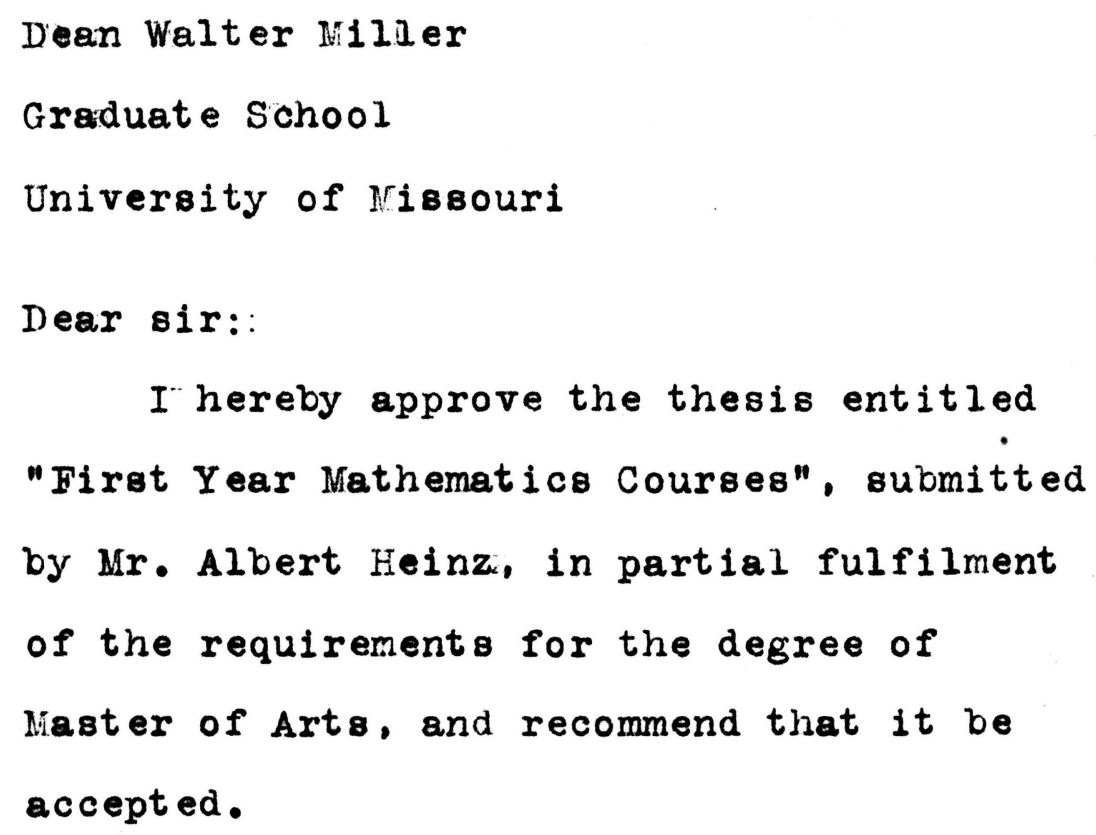




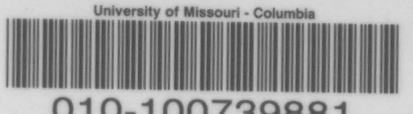

010-100739881
$378.7 \mathrm{M71}$

$X H 365$
PECEIT

DCT 2018 
MU Libraries

Heinz1916.txt

University of Missouri--Columbia

MU Theses and Dissertations (Pre-1920)

Local identifier

Capture information

Date captured

Scanner manufacturer

Scanner mode1

Scanning system software

optical resolution

color settings

File types

Source information

Format

Content type

Source ID

Notes
Heinz1916

2016-05-02

Zeutsche1

OS 15000

Omniscan v.12.4 SR4 (1947) 64-bit

$600 \mathrm{dpi}$

grayscale, 8 bit

tiff

Book

Text

010-100739881

Pages typed and single-sided.

Title page has perforated property stamp.

Ca11 number written on page after title page.

Purple ink property stamp on page 62 .

University correspondence with signature

follows page 63 .

Inside back cover has stamp, barcode, and call number.

Page numbers and some text is typed in red ink.

Tiff compressed with LZW before conversion to pdf Adobe Photoshop CS5

$600 \mathrm{dpi}$

Grayscale

pdf

Grayscale pages cropped, canvassed, and brightened.

Pages with red ink scanned in grayscale.

Blank pages removed. 